\title{
Three-Parameter Kinematic Theory for Shear-Dominated Reinforced Concrete Walls
}

\author{
Boyan I. Mihaylov ${ }^{1}$; Pia Hannewald²; and Katrin Beyer, M.ASCE ${ }^{3}$
}

\begin{abstract}
This paper is aimed at addressing the need for physically accurate and computationally effective models for predicting the response of shear-dominated reinforced concrete walls. The presented theory is based on a three-degree-of-freedom kinematic model for the deformation patterns in walls with aspect ratios smaller than approximately 3. In the kinematic model, the wall is divided into two parts - a rigid block and a fan of struts - by a diagonal crack. The mechanisms of shear resistance across this crack are modeled with nonlinear springs to capture the prepeak and postpeak shear behavior of the member. The base section of the wall is also modeled to account for yielding of the reinforcement and crushing of the concrete. It is shown that this approach captures well the global and local deformations measured in a test specimen with detailed instrumentation. A more comprehensive validation of the theory is performed with 34 wall tests from the literature. The obtained peak load experimental-to-predicted ratios have an average of 1.03 with a coefficient of variation of $11.6 \%$, while these values for the drift capacity are 0.99 and 16.4\%. DOI: 10.1061/(ASCE)ST.1943-541X.0001489. ( $) 2016$ American Society of Civil Engineers.
\end{abstract}

Author keywords: Reinforced concrete walls; Shear; Deformation patterns; Kinematic model; Drift capacity; Concrete and masonry structures.

\section{Introduction}

Many reinforced concrete (RC) wall structures were built before the introduction of modern seismic design guidelines, and as a result feature smaller lateral resistance than today's seismic codes require. Furthermore, many of these structures do not meet the current capacity design requirements, and therefore are susceptible to shear failures that limit their deformation capacity. However, to determine if any retrofit measures to increase the lateral resistance or ductility are necessary, the seismic behavior of the structure should be assessed using methods that account explicitly for the inelastic deformation capacity of the walls. Since walls expected to develop brittle shear failures will likely require a more costly retrofit than walls possessing certain ductility, it becomes very important to be able to accurately predict the lateral drift at which shear failure will occur. In addition, due to the time pressures that engineers often find themselves at work, methods for predicting the

${ }^{1}$ Assistant Professor, Structural Engineering Group, Dept. of ArGEnCo, Univ. of Liege, Bât. B52, Quartier Polytech 1, Allée de la Découverte 9, 4000 Liege, Belgium (corresponding author). E-mail: boyan.mihaylov@ ulg.ac.be

${ }^{2}$ Résonance Ingénieurs-Conseils SA, rue Jacques Grosselin 21, 1227 Carouge, Suisse; formerly, Ph.D. Student, Earthquake Engineering and Structural Dynamics Laboratory (EESD), School of Architecture, Civil and Environmental Engineering (ENAC), École Polytechnique Fédérale de Lausanne (EPFL), 1015 Lausanne, Switzerland. E-mail: pia .hannewald@ resonance.ch

${ }^{3}$ Assistant Professor, Earthquake Engineering and Structural Dynamics Laboratory (EESD), School of Architecture, Civil and Environmental Engineering (ENAC), École Polytechnique Fédérale de Lausanne (EPFL), 1015 Lausanne, Switzerland. E-mail: katrin.beyer@epfl.ch

Note. This manuscript was submitted on November 19, 2014; approved on December 10, 2015; published online on March 9, 2016. Discussion period open until August 9, 2016; separate discussions must be submitted for individual papers. This paper is part of the Journal of Structural Engineering, (C) ASCE, ISSN 0733-9445. force-deformation characteristics of walls should be relatively simple and computationally inexpensive.

The simplest approach to estimate the drift at shear failure of walls is empirical expressions [ASCE/SEI 41-6 (ASCE 2007); EC8-3 (CEN 2005); Biskinis and Fardis 2010]. However, as the shear behavior of walls is affected by a large number of parameters, such expressions are sensitive to the data sample on which they are based. The empirical approach has also been used to develop lumped plasticity models that account for the effects of shear (Hidalgo et al. 2002). At the other end of the spectrum of complexity are nonlinear finite or discrete element models, which use a large number of degrees of freedom to discretize the deformed shape of the member. These models require a significant amount of time for modeling and computation as well as considerable expertise to use safely. Researchers therefore have developed simpler physical models such as strut-and-tie-based models (Panagiotou et al. 2012), stringer panel models (Blaauwendraad and Hoogenboom 1996), and fiber element models (Martinelli 2008). These approaches, however, still require significant discretization of the member.

This paper presents a three-parameter kinematic theory (3PKT), which uses only three degrees of freedom (DOFs) to describe the deformation patterns of diagonally cracked walls with rectangular sections. It originates from a two-parameter kinematic theory (2PKT) for deep beams (Mihaylov et al. 2013), which is extended in order to account for the shortening of the member caused by axial forces. The 3PKT approach aims to capture in a time-efficient way the complete prepeak and postpeak response of sheardominated walls, including the loss of axial load capacity. The common characteristic of shear-dominated walls is the development of major diagonal cracks. The model predicts the response of such walls that fail either in shear along the diagonal cracks or at the base section under the combined action of flexure and shear. The failure along the diagonal cracks can occur either in a brittle manner prior to yielding of the flexural reinforcement, or in a more ductile manner after flexural yielding. 


\section{Kinematics of Shear Walls}

The approach presented here is based on the idea that the complete deformation pattern of diagonally cracked cantilever walls can be described by a kinematic model with only three DOFs. This idea stems from measured deformed shapes of deep beams (Mihaylov et al. 2010) and shear walls such as the test specimen shown in Fig. 1 (wall VK3, Bimschas 2010). This specimen was subjected to a constant vertical load $N=1,300 \mathrm{kN}$ and cyclic lateral displacements $\Delta$ with increasing amplitude. Fig. 1(b) depicts the crack patterns of the wall at shear failure. The failure occurred at $\Delta=$ $42 \mathrm{~mm}$ along a wide diagonal crack with crushing of the concrete in what will be referred to as the critical loading zone (CLZ). The measured deformed shape of the wall at failure is shown in Fig. 1(c) with a mesh of triangles, where the shadows of gray correspond to the sum of the average principal strains $\left|\varepsilon_{1}\right|+\left|\varepsilon_{2}\right|$ in each triangle. From this diagram, it can be seen that the deformations concentrated along the diagonal of the wall while the concrete block above the diagonal cracks remained almost undeformed. Therefore, this block is modeled as a rigid body with three DOFs and forms the basis of a kinematic model for the entire wall.

Fig. 2 shows the proposed kinematic model for shear-dominated cantilever walls. The first DOF of the model is the average tensile strain in the flexural reinforcement $\left(\varepsilon_{t, \text { avg }}\right)$ within the cracked zone below the critical crack [Fig. 2(a)]. The length over which the strains are averaged is denoted as $l_{t}$. The critical shear crack is approximated with a straight line at an angle $\alpha_{1}$ with respect to the vertical axis. It can be seen that strain $\varepsilon_{t \text {,avg }}$ is associated with rotation of the rigid block about point $\mathrm{A}$ by an angle $\varepsilon_{t, \text { avg }} l_{t} / d$, and with deformations in the concrete below the critical crack. This bottom part of the wall is modeled with a series of rigid radial struts pinned at point $\mathrm{A}$ and connected to the tension reinforcement (fan of struts). The rotation of each strut about point A is proportional to the elongation of the reinforcement between the base of the wall and the point where the strut connects to the reinforcement.
This deformation pattern can be associated with flexural deformations.

The second DOF of the kinematic model is the horizontal displacement $\Delta_{c}$ in the critical loading zone (CLZ) [Fig. 2(b)]. In this deformation pattern, the rigid block translates laterally while the fan remains undeformed since $\varepsilon_{\text {tavg }}$ is zero. At the top of the critical diagonal crack, displacement $\Delta_{c}$ develops over a transition zone of length $l_{k}$ in which the flexural reinforcement is subjected to double curvature. The kinematics related to DOF $\Delta_{c}$ can be associated with shear deformations.

Degrees of freedom $\varepsilon_{t, \text { avg }}$ and $\Delta_{c}$ are adopted from the 2PKT for deep beams, while a third DOF is introduced for the modeling of walls: the downward displacement $\Delta_{c x}$ in the CLZ [Fig. 2(c)]. Displacement $\Delta_{c x}$ is associated with rotation of the rigid block about point $\mathrm{B}$ by an angle $\Delta_{c x} / d$. This rotation can result in a contact between the rigid block and the concrete below the critical diagonal crack in the vicinity of the CLZ. It is apparent from Fig. 2(c) that DOF $\Delta_{c x}$ is related to the action of the axial load $N$, which drives the rigid block downwards.

When the deformation patterns associated with the three DOFs are superimposed, they produce the complete deformed shape of the wall shown in Fig. 1(d). The displacement of each point from the wall with respect to the coordinate system $x-z$ is expressed as a sum of the displacements associated with each deformation pattern. Based on small-displacement kinematics, it can be shown that the displacements of the points of the rigid block are given by

$$
\begin{gathered}
\delta_{x}(x, z)=\frac{\varepsilon_{t, \text { avg }} l_{t}}{d}(h-z)+\frac{\Delta_{c x}}{d}(h-d-z) \\
\delta_{z}(x, z)=\left(\frac{\varepsilon_{t, \text { avg }} l_{t}}{d}+\frac{\Delta_{c x}}{d}\right) x+\Delta_{c}
\end{gathered}
$$

while the displacements in the fan below the critical diagonal crack are (Mihaylov et al. 2013)

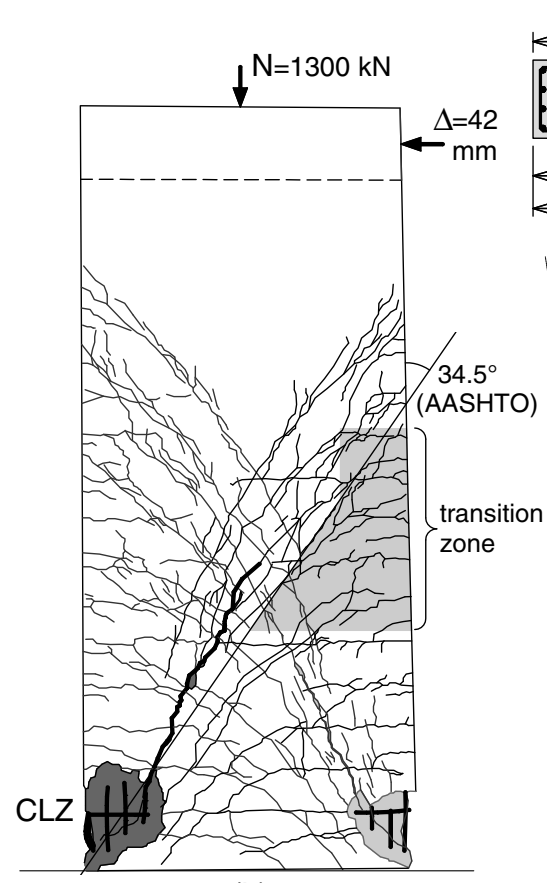

(b)

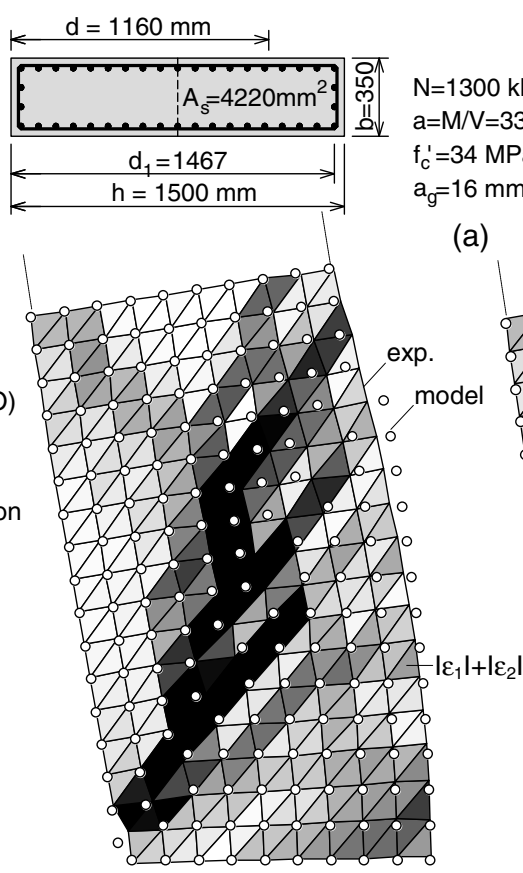

(c)

(a)
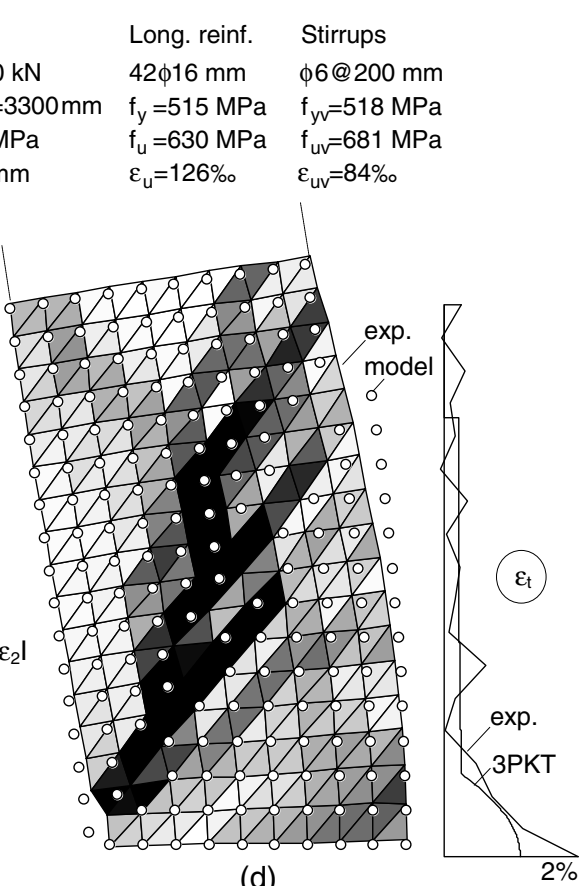

(d)

Fig. 1. Deformation patterns in shear-dominated walls—specimen VK3 (data from Bimschas 2010): (a) wall properties; (b) crack pattern at failure; (c) deformations at failure $\times 15$ and 3PK model with fitted DOFs; (d) deformations at failure and 3PK model with predicted DOFs 


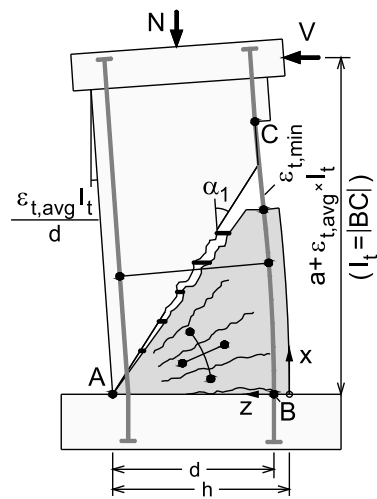

(a)

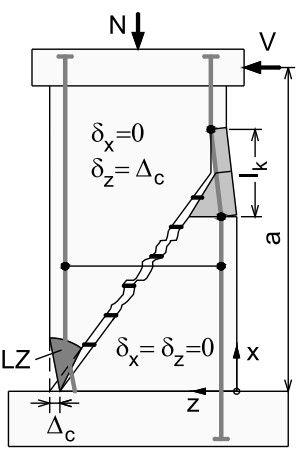

(b)

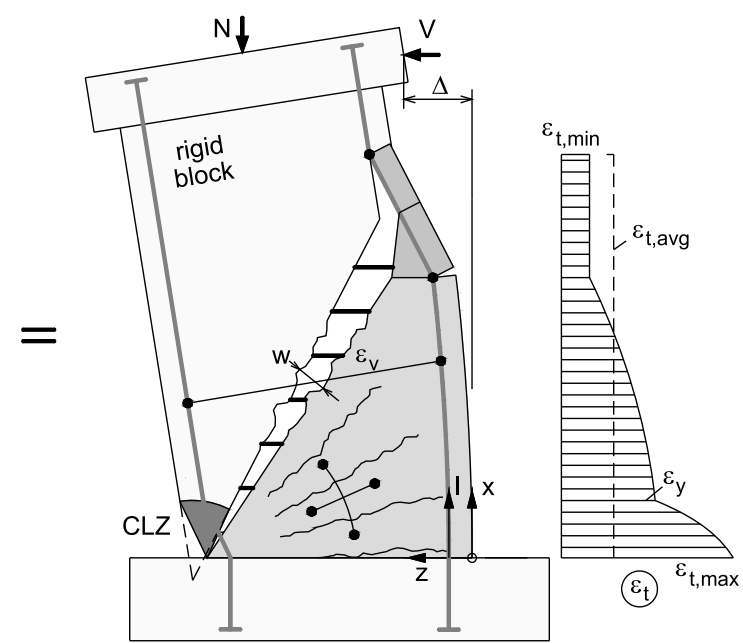

(d)

$$
\begin{gathered}
\delta_{x}(x, z)=\varepsilon_{t, \mathrm{avg}} x \\
\delta_{z}(x, z)=\frac{\varepsilon_{t, \mathrm{avg}} x^{2}}{h-z}
\end{gathered}
$$

Note that the displacements in the fan depend only on DOF $\varepsilon_{t, \text { avg }}$, which causes rotation of the radial struts about point A, and therefore results in both vertical and horizontal displacements.

To complete the formulation of the kinematic model, it is necessary to estimate the angle of the critical crack $\alpha_{1}$ and lengths $l_{k}$ and $l_{t}$. Angle $\alpha_{1}$ is obtained from a shear strength calculation according to the AASHTO code provisions (AASHTO 2007; Bentz et al. 2006). Since the steepest cracks in short walls typically propagate along the diagonal of the wall, angle $\alpha_{1}$ should remain larger than or equal to the angle $\alpha$ of the wall diagonal. Fig. 3 shows angles $\alpha_{1}$ and $\alpha$ as well as the equations necessary to calculate lengths $l_{k}$ and $l_{t}$. Length $l_{k}$ is evaluated as the sum of the expressions for $l_{0}$ and $\left(l_{k}-l_{0}\right)$, where $l_{0}$ is the portion of $l_{k}$ below the critical crack. The expressions for $l_{0}$ and $\left(l_{k}-l_{0}\right)$ are derived by considering one crack below and one above the critical diagonal crack, taking also into account limits imposed by the wall height and the width of an effective tension zone $\min [2.5(h-d), h / 2]$. The crack spacing along the flexural reinforcement $s_{c r}$ is estimated based on Model Code 90 [MC90 (CEB-FIP 1990)] by considering the reinforcement ratio $\rho_{l 1}$ in the effective tension zone. The expression for $l_{t}$ shown in the bottom of Fig. 3 stems directly from the diagram in the figure. Fig. 3 also shows the geometry of the critical loading zone (CLZ), which will be discussed later in the paper.

To check whether the assumed kinematics models well the deformations in shear-dominated walls, Eqs. (1)-(4) are applied to specimen VK3 to compute the location of the vertices of the triangles (grid points) from the measured deformed shape in Fig. 1(c). The effective depth $d$ of the wall section is calculated by considering the centroid of the longitudinal reinforcement in one-half of the section $(d=1,160 \mathrm{~mm})$. The area of this reinforcement $A_{s}=$ $4,220 \mathrm{~mm}^{2}$ is also the area of the flexural reinforcement in the kinematic model. According to an AASHTO shear strength calculation, the angle of the critical crack is $\alpha_{1}=34.5^{\circ}>\alpha=25.8^{\circ}$. This angle is shown in Fig. 1(b) together with the predicted transition zone at the top of the critical crack. The three DOFs

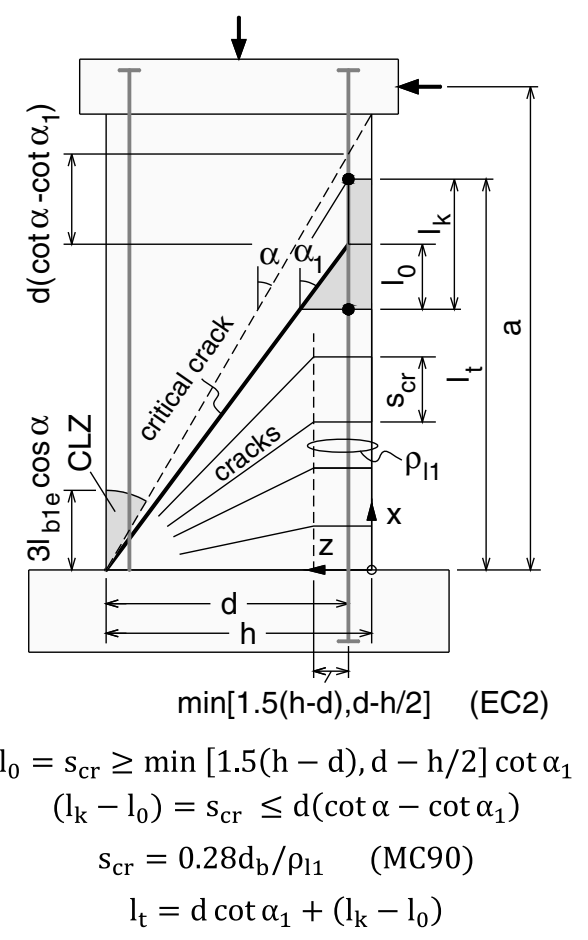

Fig. 3. Geometry of kinematic model 


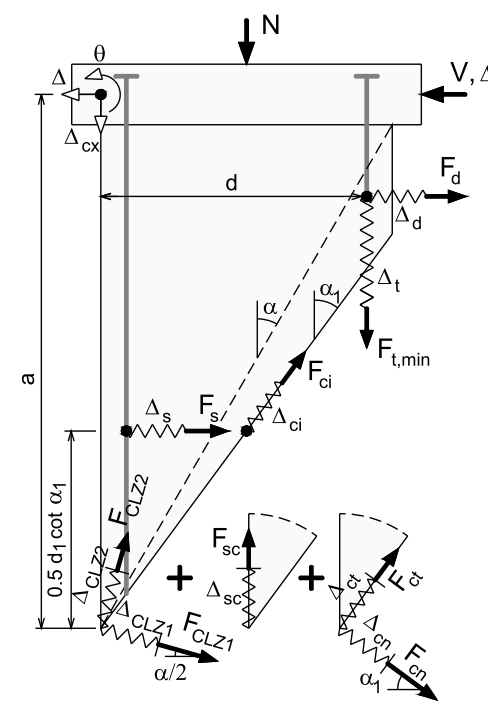

(a)

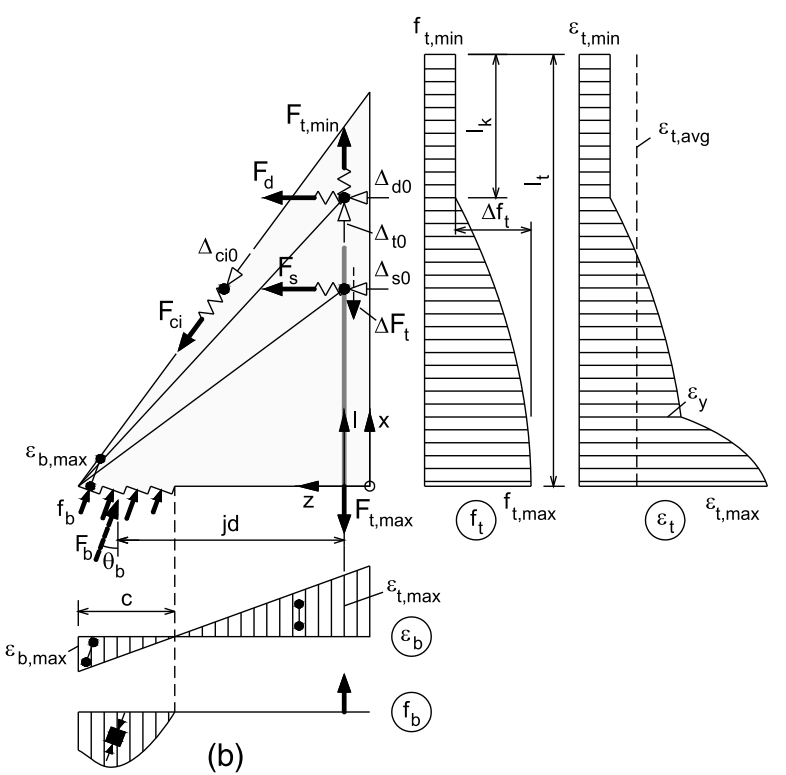

Fig. 4. Spring model representing the load-bearing mechanisms in shear walls: (a) rigid block above the critical diagonal crack; (b) fan below the critical diagonal crack

of the kinematic model are determined such that the error of the computed locations of the grid points above the critical crack is minimized, resulting in $\varepsilon_{t, \mathrm{avg}}=4.06 \times 10^{-3}, \Delta_{c}=2.5 \mathrm{~mm}$, and $\Delta_{c x}=6.0 \mathrm{~mm}$. The results obtained from Eqs. (1)-(4) for the location of the grid points are shown in Fig. 1(c) with dots. It can be seen that the kinematic model with only three DOFs captures well the measured displacement field of the wall.

In addition to the displacement field, the kinematic model can also be used to estimate the width of the critical diagonal crack $w$ half-way along the crack. This width is obtained as the sum of the widths associated with the three DOFs of the model

$$
w=\left[\frac{\left(\varepsilon_{t, \min } l_{k}\right)}{2 \sin \alpha_{1}} \frac{h}{d}+\Delta_{c} \cos \alpha_{1}+\frac{\Delta_{c x}}{d}\left(\frac{h}{2 \sin \alpha_{1}}-d \sin \alpha_{1}\right)\right] \frac{1}{n_{c r}}
$$

where $\varepsilon_{t, \text { min }}=$ strain in the flexural reinforcement within length $l_{k}$. The expression in the brackets is derived directly from the deformation patterns in Figs. 2(a-c) assuming a single dominant diagonal crack. In members with sufficient web reinforcement, however, this width will be distributed among several major cracks as observed in specimen VK3 [Fig. 1(b)]. The number of these cracks $n_{c r}$ can be estimated as $l_{k} / s_{c r}$ for walls with longitudinal web reinforcement $\rho_{l \text {,web }} \geq 0.2 \%$ and 1 otherwise. The ratio $l_{k} / s_{c r}$ is the number of cracks within the transition zone between the fan and the rigid block on the flexural tension side of the section. These cracks tend to merge into a single wide crack in the web if they are not controlled by web reinforcement. Specimen VK3 had $\rho_{l, \text { web }}$ of $1.23 \%$ and therefore $n_{c r}=l_{k} / s_{c r}=915 / 319 \approx 3$. If for now it is assumed that $\varepsilon_{t, \text { min }} \approx 0.5 \varepsilon_{t, \text { avg }}$, and if the DOFs from the previous comparison are substituted in Eq. (5), a crack width of $2.5 \mathrm{~mm}$ is obtained. This value corresponds reasonably well to the measured widths of the critical diagonal cracks at shear failure, which varied between 1.7 and $2.3 \mathrm{~mm}$.

Despite these results, it should be noted that the assumptions made in the development of the kinematic model impose certain limits on its applicability. The model is suitable for walls with rectangular sections subjected to single curvature (cantilever walls) that develop major shear cracks. Therefore, failure modes characterized by small stresses in the transverse reinforcementpure flexural failures, web crushing, or sliding shear failures at the base of the wall-are not adequately captured by the kinematic model. To set clear criteria for the applicability of the model, it will be assumed that pure flexural failures and sliding shear failures would not likely occur if the 3PKT approach predicts that the transverse reinforcement yields before the flexural reinforcement. Since web crushing failures are more likely to occur under high compression forces, the axial load ratio $N / b h f_{c}^{\prime}$ should be smaller than 0.2 . The other limits of applicability of the model are as follows: (1) an aspect ratio $\leq 3.0$, to take into account that in slender walls the assumption made for a rigid block above the critical crack is not valid; (2) a wall-height-to-thickness ratio $\leq 25$ to ensure against out-of-plane instability (ACI 2011); (3) normal strength concrete $\left(f_{c}^{\prime} \leq 60 \mathrm{MPa}\right)$; (4) no lap-splices in the base section; and (5) no diagonal shear reinforcement.

In its range of applicability, the three-parameter kinematic model forms the basis of the three-parameter kinematic theory (3PKT) for predicting the load-displacement response of RC walls. The DOFs of the model will be predicted by combining the kinematic equations with equilibrium equations and constitutive relationships for the load-bearing mechanisms in the wall. Two potential failure planes will be considered: the diagonal crack and the horizontal section at the base. The modeling of the former failure mode will be discussed first.

\section{Forces Transferred across the Critical Diagonal Crack}

Fig. 4(a) shows a free-body diagram of the rigid block of the kinematic model. The block interacts with the foundation through the forces depicted at the tip of the CLZ and with the fan through 
the forces across the critical diagonal crack. The latter forces include the aggregate interlock force $F_{c i}$, the tension in the stirrups $F_{s}$, the tension in the flexural reinforcement $F_{t, \min }$, and the force due to dowel action of the flexural reinforcement $F_{d}$. In the 3PKT, these load-bearing mechanisms are modeled with nonlinear springs across the critical crack. The locations where the springs are connected on both sides of the crack are marked with solid dots. This section outlines how to evaluate the deformations and the forcedeformation relationships of these springs, while the springs at the tip of the CLZ are discussed in the next section. The deformations in the springs will be derived from the kinematic model as a function of the three DOFs of the model.

The aggregate interlock spring $F_{c i}$ is located half-way along the critical diagonal crack and is parallel to the crack. The deformation of this spring $\Delta_{c i}$ corresponds to the slip displacement between the crack faces and can be expressed as

$$
\Delta_{c i}=\Delta_{c} \sin \alpha_{1}+\Delta_{c x} \cos \alpha_{1}-\Delta_{c i 0} \geq 0
$$

The first two terms of this equation are derived from the deformation patterns in Figs. 2(b and c) (DOFs $\Delta_{c}$ and $\Delta_{c x}$ ) while DOF $\varepsilon_{t, \text { avg }}$ does not contribute to the slip displacement. The third term of the equation is the displacement of the end of spring $F_{c i}$ attached to the fan [Fig. 4(b)]. More precisely, $\Delta_{c i 0}$ is the shortening of the bottom half of the top strut from the fan, which reduces the crack slip. Displacement $\Delta_{c i 0}$ and the other end displacements of the springs attached to the fan will be referred to as offset displacements and will be derived in section "Calculating the Fan." The slip displacement $\Delta_{c i}$ and crack width $w$ [Eq. (5)] are used to evaluate the shear stress on the crack $v_{c i}$ according to a contact density model (CDM) proposed by Li et al. (1989). Stress $v_{c i}$ is in turn used to evaluate the aggregate interlock force $F_{c i}$ as follows:

$$
F_{c i}=0.18 v_{c i}\left(\Delta_{c i}, w\right) b d_{1} / \sin \alpha_{1}
$$

where quantity $b d_{1} / \sin \alpha_{1}=$ surface of the critical crack from the base of the wall to the furthest layer of flexural reinforcement [see dimensions $b$ and $d_{1}$ in Fig. 1(a)]. Factor 0.18 accounts for a simplification made in the use of the contact density model. In addition to shear stresses on the crack, the CDM accounts for compressive stresses, which increase the aggregate interlock resistance. These clamping stresses are neglected in the 3PKT; therefore, the shear resistance obtained from the CDM is reduced by a factor of 0.18 adopted from Vecchio and Collins (1986). This factor was proposed as the ratio of the shear capacity of the crack without clamping to the shear capacity of the crack with a maximum clamping stress.

The second spring located half-way along the critical crack is the spring representing the transverse reinforcement. The deformation of this spring is equal to the horizontal expansion of the web of the wall at distance $0.5 d_{1} \cot \alpha_{1}$ from the base

$$
\Delta_{s}=\left(\frac{\varepsilon_{t, \mathrm{avg}} l_{t}}{d}+\frac{\Delta_{c x}}{d}\right) 0.5 d_{1} \cot \alpha_{1}+\Delta_{c}-\Delta_{s 0}
$$

The last term in the expression is again the offset displacement due to the deformations of the fan. The average strain in the stirrups across the web is estimated as $\varepsilon_{v}=\Delta_{s} /\left(0.9 d_{1}\right)$ and the stress in the stirrups $f_{v}$ is calculated from this strain based on a bilinear stress-strain relationship for the steel. Having obtained $f_{v}$, the force in the stirrups is calculated from

$$
\begin{aligned}
F_{s}= & A_{v} f_{v}=\rho_{v} b \cdot \max \left[d_{1} \cot \alpha_{1}-1.5 l_{b 1 e}\right. \\
& \left.-l_{0}\left(d / d_{1}\right), 0.5 d_{1} \cot \alpha_{1}\right] f_{v}
\end{aligned}
$$

where the expression in the brackets is the height over which the stirrups are activated by the expansion of the web (Mihaylov et al. 2013). Quantity $l_{b 1 e}$ in Eq. (9) is the characteristic length of the CLZ calculated from Eq. (12).

In addition to $F_{s}$, the other horizontal force acting across the critical crack is the dowel action force $F_{d}$. This force develops in the zone of transition between the fan and the rigid block where the flexural reinforcement is subjected to double curvature. Therefore, each of the $n_{b}$ bars with a total area $A_{s}$ in this zone works as a dowel of length $l_{k}$. The deformation of the spring that models this effect is equal to the relative horizontal displacement between the ends of the dowels

$$
\Delta_{d}=\left(\frac{\varepsilon_{t, \mathrm{avg}} l_{t}}{d}+\frac{\Delta_{c x}}{d}\right) l_{t}+\Delta_{c}-\Delta_{d 0}
$$

and the dowel force $F_{d}$ is obtained by modeling the dowels as fixed-fixed beams subjected to $\Delta_{d}$

$$
F_{d}=n_{b} \frac{12 E_{s} \pi d_{b}^{4}}{64 l_{k}^{3}} \Delta_{d} \leq n_{b} f_{y}\left[1-\left(\frac{F_{t, \mathrm{~min}}}{f_{y} A_{s}}\right)^{2}\right] \frac{d_{b}^{3}}{3 l_{k}}
$$

The expression before $\Delta_{d}$ in Eq. (11) is the elastic stiffness of the dowels in double curvature, while the upper limit on $F_{d}$ corresponds to the formation of plastic hinges at the ends of the dowels. The expression in the square bracket accounts for the reduction of the plastic moment capacity of the bar-dowels due to the tension force in the dowels $F_{t \text {,min }}$. This tension is modeled with the last spring across the critical crack [Fig. 4(a)]. The elongation of this spring is $\Delta_{t}=\varepsilon_{t, \text { avg }} l_{t}-\Delta_{t 0}$ and the corresponding strain in the reinforcement is $\varepsilon_{t, \min }=\Delta_{t} / l_{k}$. The stress in the reinforcement $f_{t, \text { min }}$ is obtained from strain $\varepsilon_{t, \text { min }}$ by using a bilinear stress-strain relationship for the steel, and force $F_{t, \text { min }}$ is calculated as $f_{t, \min } A_{s}$. The load-deformation response of spring $F_{t, \text { min }}$ as well as those of the other three springs crossing the critical diagonal crack are shown schematically in Fig. 5.

\section{Critical Loading Zone}

An important component of the 3PKT approach is the modeling of the critical loading zone (CLZ). In Fig. 4(a), this zone is
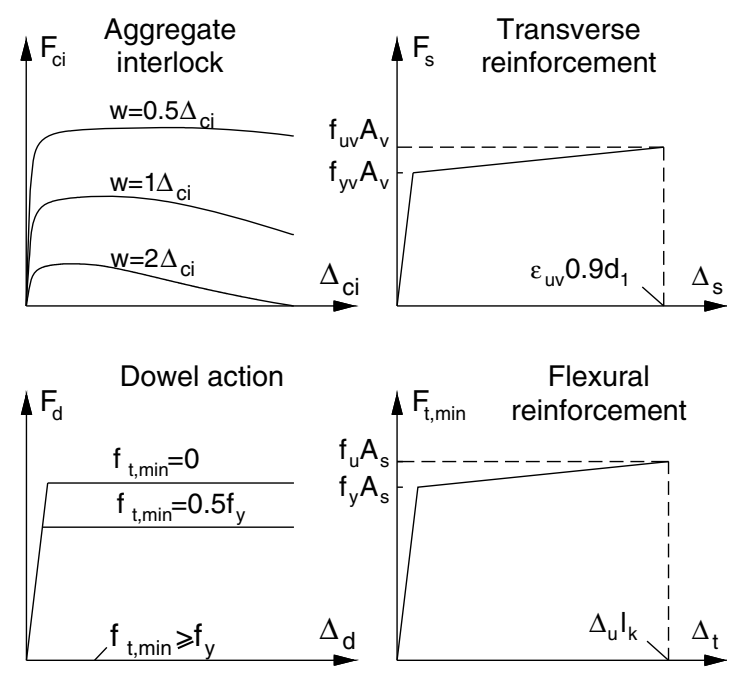

Fig. 5. Constitutive relations of springs across the critical diagonal crack 
represented by five nonlinear springs that connect the rigid block to the foundation. Springs $F_{C L Z 1}$ and $F_{C L Z 2}$ represent the compression in the concrete in the CLZ, springs $F_{c n}$ and $F_{c t}$ model a potential contact between the rigid block and the fan, and spring $F_{s c}$ models the vertical reinforcement in the CLZ.

Fig. 6(a) shows a photograph of a failed CLZ in a shear-critical wall (specimen VK6) (Hannewald et al. 2013). This zone is bound between the vertical edge of the wall and the critical diagonal crack that extends to the base of the wall. It can be seen that the failure of the CLZ occurred in a complex manner, resulting in the crushing of the concrete under the combined action of normal and shear stresses. It can also be seen that the longitudinal reinforcement buckled due to insufficient confining reinforcement in the edge zones of the wall. To model this complex behavior, it is first suggested to approximate the shape of the CLZ with a circular sector with a radius $3 l_{b 1 e} \cos \alpha$ centered at the corner of the wall [see Fig. 6(b)]. The expression for the radius is adopted from the $2 \mathrm{PKT}$ for deep beams where the characteristic length $l_{b 1 e}$ is proportional to the width of the column loading the beam (Mihaylov et al. 2013). In walls, the forces from the CLZ are defused into the foundation; therefore, the characteristic length is less clearly defined than in deep beams. For this reason, a simple expression for $l_{b 1 e}$ is proposed based on comparisons with wall tests

$$
l_{b 1 e}=0.11 \sqrt{a^{2}+h^{2}} \leq 370 \mathrm{~mm}
$$

where $\sqrt{a^{2}+h^{2}}=$ length of the diagonal of the wall ( $a=$ height of the wall and $h=$ depth of the wall's section). Details about the derivation of this expression are provided later in the paper

As evident from Fig. 6(b), the displacement of the tip of the critical loading zone $\Delta_{\text {CLZ }}$ relative to the rigid block has horizontal and vertical components equal to DOFs $\Delta_{c}$ and $\Delta_{c x}$, respectively. This displacement is associated with compressive strains and stresses in the concrete, as well as a reaction force $F_{\mathrm{CLZ}}$. In order to estimate $F_{\mathrm{CLZ}}$, it is suggested to first assume a relationship between the directions of $\Delta_{\mathrm{CLZ}}$ and $F_{\mathrm{CLZ}}$ given by angles $\alpha_{\Delta}$ and $\alpha_{F}$, respectively. This relationship should satisfy two requirements: (1) when $\alpha_{\Delta}$ equals $\alpha / 2, \alpha_{F}$ should also equal $\alpha / 2$ as required by symmetry; and (2) when $\Delta_{\mathrm{CLZ}}$ is horizontal $\left(\alpha_{\Delta}=90^{\circ}\right), F_{\mathrm{CLZ}}$ should be aligned with the diagonal of the wall $\left(\alpha_{F}=\alpha\right)$ as assumed in the modeling of deep beams. Based on these two requirements, the following expression for angle $\alpha_{F}$ is proposed:

$$
\alpha_{F}=\alpha-\eta
$$

$$
\tan \eta=\tan \frac{\alpha}{2}-2 \sin ^{2} \frac{\alpha}{2}\left[\tan \frac{\alpha}{2}+\tan \left(\alpha_{\Delta}-\alpha\right)\right]
$$

The average compressive strain in the CLZ in the direction of force $F_{\mathrm{CLZ}}$ is then calculated from

$$
\varepsilon_{\mathrm{CLZ}}=\frac{\Delta_{\mathrm{CLZ}} \cos \left(\alpha_{\Delta}-\alpha_{F}\right)}{3 l_{b 1 e} \cos \alpha}
$$

and the compressive stress $f_{c}$, CLZ is obtained from $\varepsilon_{\text {CLZ }}$ by using an appropriate stress-strain relationship for the concrete (Popovics 1970). To account for nonuniform distribution of the stresses in the CLZ, $f_{c}$,CLZ is calculated as the average stress from zero strain up to $\varepsilon_{\mathrm{CLZ}}$. If the wall has edge zones confined with hoops, the stress-strain relationship is modified to account for the confinement effect based on the model proposed by Mander et al. (1988). Finally, the reaction force $F_{\mathrm{CLZ}}$ is calculated by integrating the stress $f_{c}$,CLZ at a distance $l_{b 1 e}$ from the tip of the CLZ, as in the 2PKT for deep beams

$$
F_{\mathrm{CLZ}}=\alpha l_{b 1 e} b f_{c, \mathrm{CLZ}}
$$

Force $F_{\mathrm{CLZ}}$ and displacement $\Delta_{\mathrm{CLZ}}$ are projected on axes 1 and 2 in Fig. 6(b) to generate the load-displacement relationships of springs $F_{\mathrm{CLZ}, 1}$ and $F_{\mathrm{CLZ,2}}$. These relationships are shown in Fig. 6(c) for two cases of inclination of $\Delta_{\mathrm{CLZ}}: \alpha_{\Delta}=90^{\circ}$ and $\alpha_{\Delta}=\alpha$.

As mentioned previously, springs $F_{c n}$ and $F_{c t}$ model a potential contact between the rigid block and the fan in the vicinity of the CLZ. From Fig. 6(b), it can be seen that such contact occurs when angle $\alpha_{\Delta}$ becomes equal to $\alpha$. Spring $F_{c n}$, which is normal to the critical shear crack, is assigned a large constant stiffness in compression and zero stiffness in tension. The stiffness in compression is chosen to prevent any meaningful penetration of the rigid block into the fan. Spring $F_{c t}$ models the friction force between the rigid block and the fan, which is estimated as 0.7 times force $F_{c n}$. Evidence of the friction forces can be seen in the photo in Fig. 6(a), which shows spalling of the concrete on both sides of the critical crack due to pressure on the crack. This effect occurs at some distance from the base of the wall, but for the sake of simplicity springs $F_{c n}$ and $F_{c t}$ are placed at the tip of the CLZ.

The last contribution to the forces in the vicinity of the CLZ is provided by the vertical reinforcing bars in the zone: spring $F_{s c}$. The load-displacement response of this spring is obtained on the basis of bars with the length $l_{b 1 e}$. Therefore, the strain in the bars is estimated as $\Delta_{c x} / l_{b 1 e}$ and the stress in the bars is calculated from

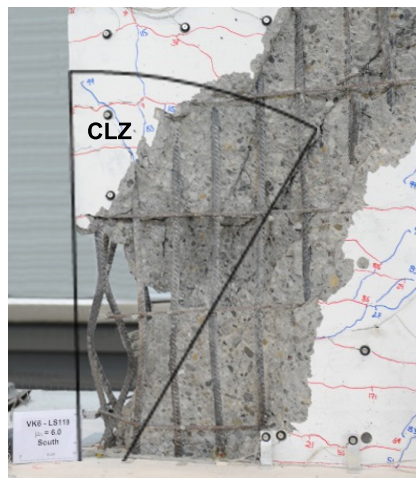

(a)

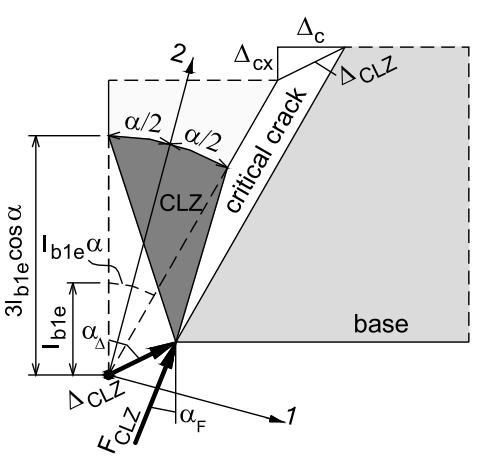

(b)

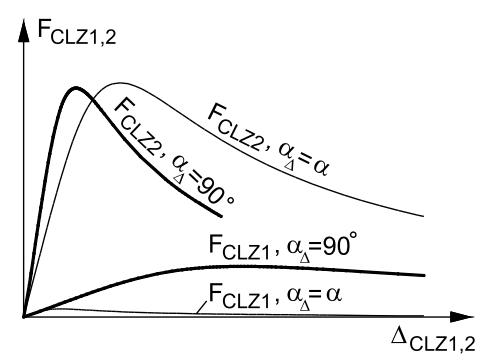

(c)

Fig. 6. Critical loading zone (CLZ): (a) CLZ after failure-wall VK6; (b) model of the critical loading zone; (c) load-displacement response 
a bilinear stress-strain relationship for the steel. The stress in the bars is multiplied by their cross-sectional area to obtain the force in the spring $F_{c s}$. To account for buckling of the bars in a simple manner, force $F_{c s}$ becomes zero if the compressive strain in the CLZ $\varepsilon_{\text {CLZ }}$ exceeds the maximum of 0.004 and the strain at peak stress of the concrete. The former strain limit corresponds to spalling of the concrete cover (Priestley et al. 2007) while the latter limit governs when the concrete in the CLZ is confined with hoops. It is assumed that when the confined concrete reaches peak stress, the hoops are yielding and the vertical bars are likely to buckle.

\section{Overview of Solution Procedure}

The solution procedure described in this section is used to compute the position of the rigid block and the lateral load $V$ when the wall is subjected to axial load $N$ and lateral displacement $\Delta$. As shown in Fig. 4, the rigid block is connected to nine nonlinear springs, and the supports of springs $F_{c i}, F_{s}, F_{d}$, and $F_{t \text {,min }}$ displace by $\Delta_{c i 0}$, $\Delta_{s 0}, \Delta_{d 0}$, and $\Delta_{t 0}$ due to the deformations of the fan. If offset displacements $\Delta_{c i 0}, \Delta_{s 0}, \Delta_{d 0}$, and $\Delta_{t 0}$ are known, and if the springs are linear, the system of rigid block and springs can be solved by using the method of displacements. In this system, the offset displacements can be treated as support settlements. The unknown displacements of the method can be for example the DOFs of the kinematic model. However, while these DOFs are suitable for the formulation of the 3PKT, they are not convenient for the numerical solution as they do not include the imposed displacement $\Delta$. Therefore, for the numerical solution, it is suggested to use DOFs $\Delta, \Delta_{c x}$, and $\theta$, where $\theta$ is the rotation of the rigid block about the point of intersection of the lateral load and the compressive edge of the wall [Fig. 4(a)]. The DOFs used for the formulation of the 3PKT can be expressed with $\Delta, \Delta_{c x}$, and $\theta$ as follows:

$$
\begin{gathered}
\varepsilon_{t, \mathrm{avg}}=\left(\theta d-\Delta_{c x}\right) / l_{t} \\
\Delta_{c}=\Delta-\theta a
\end{gathered}
$$

Taking the aforementioned into account, the following iterative procedure based on the secant stiffness approach is proposed:

1. Calculate the geometry of the kinematic model using Fig. 3 and Eq. (12). To obtain angle $\alpha_{1}$, perform a shear strength calculation according to the AASHTO code;

2. Choose $\Delta$ at which to perform calculations. The axial load $N$ is constant;

3. Assume initial values of the secant stiffness of the springs $K_{i}(i=1-9)$ and displacement offsets $\Delta_{c i 0}, \Delta_{s 0}, \Delta_{d 0}, \Delta_{t 0}$. To speed up the calculations, it is recommended to use the final values from the previous converged load stage. For the first iteration of the first load stage, use the initial tangent stiffness of the springs and $\Delta_{c i 0}=\Delta_{s 0}=\Delta_{d 0}=\Delta_{t 0}=0$;

4. Use the displacement method to calculate DOFs $\Delta_{c x}$ and $\theta$ of the rigid block under $\Delta$ and $N$. Calculate DOFs $\Delta_{c}$ and $\varepsilon_{t, \text { avg }}$ from Eqs. (17) and (18);

5. Also from the displacement method, calculate the forces in the springs crossing the critical diagonal crack $F_{c i}, F_{s}, F_{d}$, and $F_{t, \min }$;

6. Solve the fan under imposed strain $\varepsilon_{t, \text { avg }}$ and forces $F_{c i}, F_{s}, F_{d}$ to obtain updated values of offsets $\Delta_{c i 0}, \Delta_{s 0}, \Delta_{d 0}$, and $\Delta_{t 0}$. Terminate the analysis if the fan fails at the base section due to crushing of the concrete or rupture of the reinforcement. This step is discussed in detail in the next section;

7. Use DOFs $\varepsilon_{t, \text { avg }}, \Delta_{c}, \Delta_{c x}$ and offset displacements $\Delta_{c i 0}$, $\Delta_{s 0}, \Delta_{d 0}, \Delta_{t 0}$ to calculate the deformations of the springs
$\Delta_{c i}, \Delta_{s}, \Delta_{d}, \Delta_{t}, \Delta_{\mathrm{CLZ1}}, \Delta_{\mathrm{CLZ2}}, \Delta_{c t}, \Delta_{c n}, \Delta_{s c}$ based on the kinematic model and the relationships derived in section "Forces Transferred across the Critical Diagonal Crack." Calculate also the crack width $w$ by using Eq. (5);

8. Use the deformations in the springs and $w$ to calculate updated spring forces $F_{c i}, F_{s}, F_{d}, F_{t \text { min }}, F_{\mathrm{CLZ1}}, F_{\mathrm{CLZ2}}, F_{c t}, F_{c n}, F_{s c}$ as discussed in sections "Forces Transferred across the Critical Diagonal Crack" and "Critical Loading Zone";

9. Update the secant stiffness of the springs $K_{i}=F_{i} / \Delta_{i}$ $(i=1-9)$, where $F_{i}$ is the force in the $i$ th spring and $\Delta_{i}$ is the deformation of the spring;

10. Return to (4) with the new spring stiffnesses and repeat the calculations until $K_{i}$ converge to constant values; and

11. Compute the lateral load $V$ from the horizontal equilibrium of the rigid block by summing up the horizontal components of the forces in the springs.

This procedure is repeated for different values of $\Delta$ to calculate the complete $V-\Delta$ response of the wall. If $V$ begins to decrease under increasing $\Delta$ before the failure of the base section of the fan, the wall is predicted to fail in shear along the critical diagonal crack. Shear failure can either occur prior to or after yielding of the flexural reinforcement. If eventually the solution does not converge, this will indicate that the wall is heavily damaged and cannot support the vertical load $N$. This procedure provides an overview of how the 3PKT equations can be solved by decoupling the calculations for the rigid block and the fan. A more efficient detailed algorithm has been implemented in a computer code and has been made available for downloading (Mihaylov et al. 2015).

\section{Calculating the Fan}

To calculate the fan as required in step 6 of the calculation procedure, it is necessary to consider the free-body diagram in Fig. 4(b). According to this diagram, the fan is subjected to forces $F_{c i}, F_{s}, F_{d}$, and $F_{t, \text { min }}$ across the critical diagonal crack which are balanced by forces $F_{b}$ and $F_{t, \max }$ at the base section of the wall. As stated in the previous section, at each iteration the fan is solved under forces $F_{c i}, F_{s}, F_{d}$, and an imposed average strain along the flexural reinforcement $\varepsilon_{t, \text { avg }}$. The solution is iterative and can be summarized in the following steps:

1. Assume an initial value of the lever arm $j d$ of forces $F_{b}$ and $F_{t, \max }$ (for example, $j d=0.9 d$ );

2. Use the moment equilibrium of the fan about the point of application of force $F_{b}$ to obtain the force difference $\Delta F_{t}=$ $F_{t, \text { max }}-F_{t, \text { min }}$ and the corresponding stress difference $\Delta f_{t}=$ $\Delta F_{t} / A_{s}$ in the flexural reinforcement;

3. Assume a value for the stress in the flexural reinforcement at the base of the wall $f_{t, \max }$ and calculate $f_{t, \min }=f_{t, \max }-\Delta f_{t}$. To obtain the complete stress profile $f_{t}$ along the flexural reinforcement, it is assumed that $f_{t}$ follows a parabolic variation along length $l_{t}-l_{k}$ (Paulay 1971) and remains constant within $l_{k}$ as shown in Fig. 4(b). Note that the tangent to the parabola at the base section is vertical;

4. From the stress profile $f_{t}$, calculate the strain profile $\varepsilon_{t}$ by using a bilinear stress-strain relationship for the reinforcement with unloading parallel to the initial loading branch. Calculate the average strain in the reinforcement and compare it to $\varepsilon_{t, \text { avg }}$. If the two strains differ, return to step 3 and adjust the value of $f_{t, \max }$ until the strains become equal. These calculations can be performed efficiently by using the method of bisection;

5. Calculate the force $F_{b}$ from the horizontal and vertical equilibrium of the fan, taking into account that $F_{t, \min }=f_{t, \min } A_{s}$; 
6. Assume a value for the maximum compressive strain $\varepsilon_{b \text {,max }}$ in the base section of the fan [Fig. 4(b)]. This strain, together with $\varepsilon_{t, \max }$ calculated in step 4 , defines a linear strain profile across the base section with a compression zone of depth $c$. Since the shear force transferred through the compression zone of short walls is significant, strains $\varepsilon_{b}$ in this zone are assumed inclined at the same angle $\theta_{b}$ as force $F_{b}$;

7. From strains $\varepsilon_{b}$, calculate stresses $f_{b}$ in the compression zone by using an appropriate stress-strain relationship for unconfined concrete (Popovics 1970) and bilinear stress-strain curve for the reinforcement. To simplify the calculations, assume that the reinforcement in the compression zone is uniformly distributed based on the average ratio $\rho_{l}=2 A_{s} / b h$. If strain $\varepsilon_{b, \text { max }}$ exceeds 0.004 , the stresses in the reinforcement are neglected due to the likelihood of cover spalling and buckling of the reinforcing bars;

8. Integrate stresses $f_{b}$ across area $\left(c / \cos \theta_{b}\right) b$ to obtain a compressive force $F_{b}^{\prime}$, where $\left(c / \cos \theta_{b}\right)$ is the depth of the compression zone perpendicular to $F_{b}$. If force $F_{b}^{\prime}$ differs from $F_{b}$ obtained in step 5 , return to step 6 and adjust the value of $\varepsilon_{b \text {,max }}$ until $F_{b}^{\prime}$ equals $F_{b}$. These calculations can also be performed efficiently by using the method of bisection;

9. Based on the obtained stress profile $f_{b}$, calculate an updated value of the lever arm $j d$ and return to step 1. Repeat the calculations until $j d$ converges to a constant value; and

10. Using the obtained strain profiles $\varepsilon_{t}$ and $\varepsilon_{b}$ in the fan, calculate displacement offsets $\Delta_{c i 0}, \Delta_{s 0}, \Delta_{d 0}$, and $\Delta_{t 0}$ based on the kinematic assumptions made for the fan

$$
\begin{gathered}
\Delta_{c i 0}=\varepsilon_{b, \max } 0.5 d_{1} / \sin \alpha_{1} \\
\Delta_{s 0}=\frac{0.5 d_{1} \cot \alpha_{1}}{d} \int_{0}^{0.5 d_{1} \cot \alpha_{1}} \varepsilon_{t} d l \\
\Delta_{d 0}=\frac{l_{t}-l_{k}}{d} \int_{0}^{l_{t}-l_{k}} \varepsilon_{t} d l \\
\Delta_{t 0}=\int_{0}^{l_{t}-l_{k}} \varepsilon_{t} d l
\end{gathered}
$$

where $l=$ coordinate along the flexural reinforcement with an origin at the base of the wall. These integrals are evaluated numerically and the result is returned to the global iteration procedure described in the previous section.

Finally, the solution procedure for the fan provides criteria for failure of the base section of the wall due to excessive compressive or tensile stresses. If force $F_{b}$ is too large to be balanced by stresses $f_{b}$, the wall is predicted to fail with crushing of the concrete in the compression zone under the combined action of flexure and shear. Flexural failure due to rupture of the reinforcement is predicted if tensile strain $\varepsilon_{t, \max }$ reaches $0.6 \varepsilon_{u}$, where $\varepsilon_{u}$ is the strain at peak stress of the steel obtained from a monotonic tension test (Priestley et al. 2007).

\section{Predicted Behavior of Wall VK3}

In order to illustrate the effectiveness of the modeling assumptions presented, the 3PKT approach is applied to specimen VK3. Fig. 7(a) shows the measured hysteretic response of the wall in terms of shear force versus lateral displacement. It can be immediately seen that this response has a plateau, which indicates yielding of the flexural reinforcement in the base section of the wall. At a lateral displacement of $42 \mathrm{~mm}$, however, a brittle shear failure
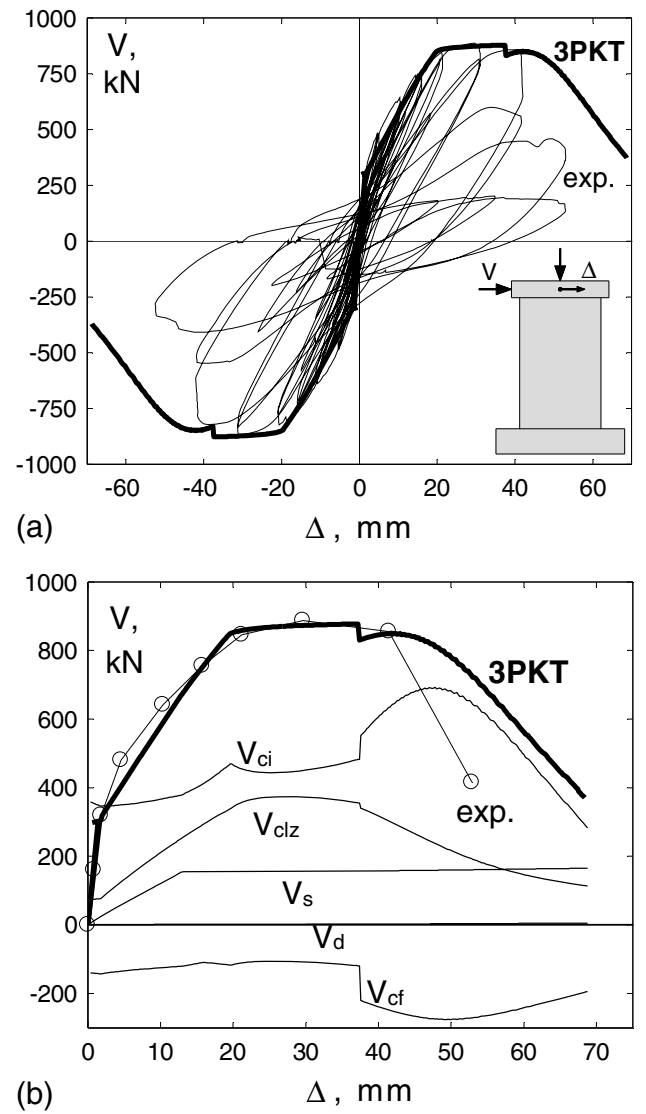

Fig. 7. Comparison of predicted and measured load-deformation response-specimen VK3 (data from Bimschas 2010): (a) loaddisplacement response; (b) components of shear resistance

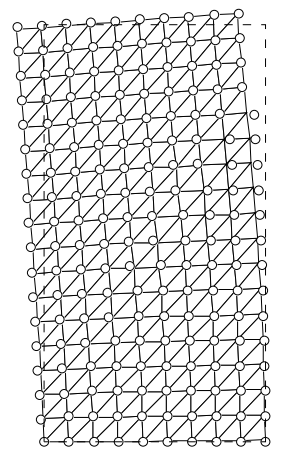

$\Delta=13.8 \mathrm{~mm}$

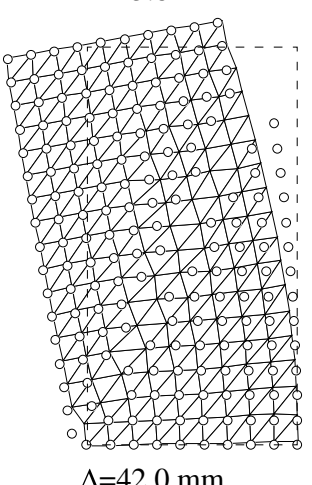

(shear failure)

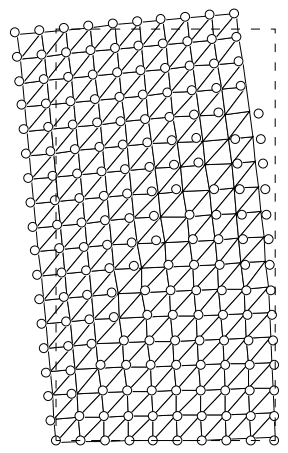

$\Delta=21.0 \mathrm{~mm}$

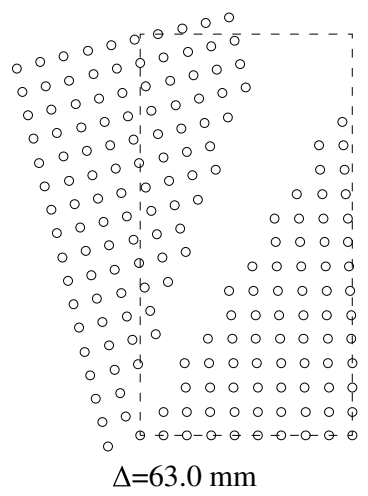

(axial load failure)
Fig. 8. Experimental (triangles) and predicted (dots) deformed shapes $\times 15-$ specimen VK3 
Table 1. Database of Wall Tests

\begin{tabular}{|c|c|c|c|c|c|c|c|c|c|c|c|c|c|c|c|c|c|}
\hline \multirow[b]{2}{*}{$\begin{array}{l}\text { Test } \\
\text { specimen }\end{array}$} & \multicolumn{4}{|c|}{ Geometry } & \multicolumn{6}{|c|}{ Reinforcement and concrete } & \multirow{2}{*}{$\begin{array}{c}n= \\
N / \\
\left(b h f_{c}^{\prime}\right)\end{array}$} & \multicolumn{2}{|c|}{ Experiment } & \multicolumn{4}{|c|}{ 3PKT results } \\
\hline & $\begin{array}{c}b \\
(\mathrm{~mm})\end{array}$ & $\begin{array}{c}h \\
(\mathrm{~mm})\end{array}$ & $\begin{array}{c}d \\
(\mathrm{~mm})\end{array}$ & $a / h$ & $\rho_{l}(\%)$ & $\begin{array}{c}\rho_{l, \text { web }} \\
(\%)\end{array}$ & $\begin{array}{c}f_{y} \\
(\mathrm{MPa})\end{array}$ & $\rho_{v}(\%)$ & $\begin{array}{c}f_{y v} \\
(\mathrm{MPa})\end{array}$ & $\begin{array}{c}f_{c}^{\prime} \\
\text { (MPa) }\end{array}$ & & $\begin{array}{l}V_{\max } \\
(\mathrm{kN})\end{array}$ & $\delta_{0.8}(\%)$ & $\begin{array}{c}l_{b 1 e}^{\prime} \\
(\mathrm{mm})\end{array}$ & $\begin{array}{c}l_{b 1 e} \\
(\mathrm{~mm})\end{array}$ & $\begin{array}{l}V_{\text {max,exp }} / \\
V_{\text {max,pred }}\end{array}$ & $\begin{array}{l}\delta_{0.8, \exp } / \\
\delta_{0.8 \text {,pred }}\end{array}$ \\
\hline $\mathrm{VK} 1^{\mathrm{a}}$ & 350 & 1,500 & 1,190 & 2.20 & 0.82 & 0.82 & 515 & 0.08 & 518 & 35.0 & 0.0707 & 729 & 1.90 & 355 & 370 & 1.03 & 0.89 \\
\hline $\mathrm{VK} 3^{\mathrm{a}}$ & 350 & 1,500 & 1,160 & 2.20 & 1.23 & 1.23 & 515 & 0.08 & 518 & 34.0 & 0.0728 & 879 & 1.35 & 310 & 370 & 1.00 & 0.82 \\
\hline $\mathrm{VK} 6^{\mathrm{b}}$ & 350 & 1,500 & 1,160 & 3.00 & 1.23 & 1.23 & 521 & 0.08 & 528 & 44.4 & 0.0558 & 666 & 2.24 & 370 & 370 & 1.01 & 0.99 \\
\hline $\mathrm{VK} 7^{\mathrm{b}}$ & 350 & 1,500 & 1,160 & 2.20 & 1.23 & 1.23 & 521 & 0.22 & 528 & 30.0 & 0.0825 & 903 & 2.25 & 370 & 370 & 1.02 & 1.16 \\
\hline $72^{c}$ & 160 & 1,700 & 1,419 & 1.00 & 1.54 & 0.50 & 384 & 0.26 & 427 & 17.6 & 0.1136 & 825 & $0.95^{\mathrm{k}}$ & 280 & 264 & 1.15 & 1.32 \\
\hline $73^{c}$ & 160 & 1,700 & 1,419 & 1.00 & 1.54 & 0.50 & 384 & 0.26 & 427 & 21.2 & 0.0943 & 740 & $0.77^{\mathrm{k}}$ & 260 & 264 & 0.95 & 1.02 \\
\hline $74^{\mathrm{c}}$ & 160 & 1,700 & 1,419 & 1.00 & 1.54 & 0.50 & 384 & 0.57 & 430 & 21.2 & 0.0943 & 830 & 0.89 & 220 & 264 & 0.93 & 0.79 \\
\hline $75^{\mathrm{c}}$ & 160 & 1,700 & 1,419 & 1.00 & 1.54 & 0.50 & 384 & 0.57 & 430 & 14.0 & 0.1429 & 825 & 1 & 260 & 264 & 1.05 & - \\
\hline $82^{c}$ & 160 & 850 & 735 & 2.00 & 2.31 & 0.40 & 388 & 0.57 & 430 & 21.2 & 0.0943 & 328 & 1 & 250 & 209 & 0.97 & - \\
\hline $83^{c}$ & 160 & 850 & 735 & 2.00 & 2.31 & 0.40 & 388 & 0.57 & 430 & 18.2 & 0.1099 & 340 & l & 270 & 209 & 1.01 & - \\
\hline$S 9^{d}$ & 100 & 1,180 & 885 & 1.12 & 0.99 & 0.99 & 560 & 0 & - & 29.2 & 0.0755 & 342 & $0.80^{\mathrm{k}}$ & 240 & 195 & 1.17 & 1.10 \\
\hline $\mathrm{S} 10^{\mathrm{d}}$ & 100 & 1,180 & 1,004 & 1.12 & 2.91 & 1.00 & 513 & 0.98 & 496 & 31.0 & 0.0716 & 670 & $0.92^{\mathrm{k}}$ & 250 & 195 & 1.12 & 1.01 \\
\hline $\mathrm{SW} 4^{\mathrm{e}}$ & 60 & 600 & 511 & 2.10 & 2.82 & 0.50 & 535 & 0.39 & 545 & 36.9 & 0 & 107 & 1.73 & 150 & 154 & 0.91 & 0.91 \\
\hline $\mathrm{SW}^{\mathrm{e}}$ & 60 & 600 & 545 & 2.10 & 3.01 & 0.47 & 500 & 0.31 & 400 & 31.8 & 0 & 113 & 0.95 & 150 & 154 & 0.96 & 0.94 \\
\hline $\mathrm{SW6}^{\mathrm{e}}$ & 60 & 600 & 511 & 2.10 & 2.82 & 0.31 & 535 & 0.31 & 400 & 38.6 & 0 & 113 & 1.67 & 150 & 154 & 0.98 & 0.93 \\
\hline $\mathrm{SW}^{\mathrm{e}}$ & 60 & 600 & 545 & 2.10 & 3.01 & 0.47 & 500 & 0.39 & 545 & 32.0 & 0 & 127 & 1.77 & 170 & 154 & 1.05 & 1.19 \\
\hline $\mathrm{SW}^{\mathrm{e}}$ & 60 & 600 & 515 & 2.10 & 2.93 & 0.31 & 430 & 0.42 & 400 & 45.8 & 0 & 94.0 & $2.00^{\mathrm{k}}$ & 180 & 154 & 0.92 & 1.04 \\
\hline $\mathrm{SW}^{\mathrm{e}}$ & 60 & 600 & 515 & 2.10 & 2.93 & 0.31 & 430 & 0.56 & 400 & 38.9 & 0 & 103 & 2.04 & 165 & 154 & 1.01 & 1.18 \\
\hline Wall2 ${ }^{\mathrm{f}}$ & 100 & 2,000 & 1,585 & 0.33 & 0.80 & 0.70 & 435 & 0.26 & 425 & 22.0 & 0 & 684 & 1.80 & 270 & 254 & 0.99 & 0.93 \\
\hline $\mathrm{TW} 2^{\mathrm{g}}$ & 152 & 1,219 & 1,071 & 2.00 & 2.84 & 0.61 & 477 & 0.61 & 443 & 48.6 & 0.0730 & 730 & 2.99 & 300 & 300 & 0.95 & 1.06 \\
\hline $\mathrm{TW}^{\mathrm{g}}$ & 152 & 1,219 & 1,064 & 1.50 & 1.31 & 0.33 & 472 & 0.33 & 516 & 48.8 & 0.0770 & 589 & 3.30 & 250 & 242 & 0.95 & 0.88 \\
\hline $\mathrm{TW}^{\mathrm{g}}$ & 152 & 1,219 & 1,057 & 1.50 & 2.54 & 0.73 & 476 & 0.73 & 443 & 55.8 & 0.0640 & 841 & 2.97 & 300 & 242 & 0.93 & 1.28 \\
\hline $\mathrm{TW}^{\mathrm{g}}$ & 152 & 1,219 & 1,064 & 1.50 & 2.46 & 0.61 & 476 & 0.61 & 443 & 57.5 & 0.0160 & 665 & 2.42 & 300 & 242 & 0.87 & 1.11 \\
\hline $\mathrm{SW}^{\mathrm{h}}$ & 203 & 3,050 & 2,290 & 0.33 & 1.00 & 1.00 & 462 & 1.00 & 462 & 29.7 & 0 & 3,230 & 1.37 & 350 & 353 & 1.39 & 0.74 \\
\hline SW6 ${ }^{\mathrm{h}}$ & 203 & 3,050 & 2,290 & 0.33 & 0.67 & 0.67 & 462 & 0.67 & 462 & 26.2 & 0 & 2,540 & 2.27 & 350 & 353 & 1.27 & 1.05 \\
\hline SW $9^{\mathrm{h}}$ & 203 & 3,050 & 2,290 & 0.54 & 1.50 & 1.50 & 462 & 0.67 & 462 & 29.7 & 0 & 2,820 & 1.18 & 460 & 370 & 1.12 & 0.91 \\
\hline SW10 & 203 & 3,050 & 2,290 & 0.54 & 1.50 & 1.50 & 462 & 0.33 & 462 & 31.7 & 0 & 2,350 & 1.08 & 360 & 370 & 1.00 & 0.96 \\
\hline SW12 & 70 & 750 & 573 & 1.10 & 2.68 & 2.45 & 470 & 1.10 & 520 & 47.9 & 0.100 & 340 & 1 & 140 & 123 & 1.18 & - \\
\hline SW15 & 70 & 750 & 573 & 1.10 & 2.68 & 2.45 & 470 & 1.10 & 520 & 37.8 & 0.100 & 320 & 1 & 180 & 123 & 1.18 & - \\
\hline $\mathrm{SW} 22^{\mathrm{i}}$ & 65 & 650 & 499 & 2.12 & 2.86 & 2.51 & 470 & 0.82 & 520 & 44.9 & 0.100 & 150 & 1 & 220 & 167 & 1.03 & - \\
\hline SW $26^{i}$ & 65 & 650 & 499 & 2.12 & 2.86 & 2.51 & 470 & 0.40 & 520 & 25.5 & 0 & 123 & 1 & 200 & 167 & 1.16 & - \\
\hline WR- $-0^{j}$ & 200 & 1,500 & 1,250 & 2.00 & 0.67 & 0.36 & 449 & 0.31 & 342 & 27.6 & 0.100 & 394 & 2.07 & 290 & 369 & 0.91 & 0.66 \\
\hline WR-10 $0^{\mathrm{j}}$ & 200 & 1,500 & 1,250 & 2.00 & 0.67 & 0.36 & 449 & 0.31 & 342 & 27.6 & 0.100 & 397 & 2.88 & 290 & 369 & 0.92 & 0.91 \\
\hline WR-200 & 200 & 1,500 & 1,250 & 2.00 & 0.67 & 0.36 & 449 & 0.31 & 342 & 27.6 & 0.100 & 415 & 2.75 & 280 & 369 & 0.96 & 0.87 \\
\hline Average & & & & & & & & & & & & & & & & 1.03 & 0.99 \\
\hline $\mathrm{COV}$ & & & & & & & & & & & & & & & & $11.6 \%$ & $16.4 \%$ \\
\hline
\end{tabular}

Note: Abbreviations TW2-TW5 correspond to the original names as follows: TW2 is RW-A20-P10-S63; TW3 is RW-A15-P10-S51; TW4 is RW-A15-P10S78; TW5 is RW-A15-P2.5-S64; $\delta_{0.8}=$ drift corresponding to a $20 \%$ drop of lateral resistance; $l_{b 1 e}^{\prime}=$ characteristic length of the CLZ, which results in the best match between calculated and measured ultimate response; $l_{b 1 e}=$ characteristic length calculated from Eq. (12).

${ }^{\mathrm{a} B i m s c h a s}$ (2010).

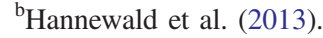

${ }^{c}$ Hirosawa (1975).

dMaier and Thürlimann (1985).

${ }^{\text {e}}$ Pilakoutas and Elnashai (1995).

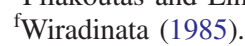

${ }^{\mathrm{g}}$ Tran and Wallace (2012).

${ }^{\mathrm{h}}$ Luna et al. (2015).

${ }^{\mathrm{i}}$ Lefas et al. (1990).

${ }^{\mathrm{j}} \mathrm{Oh}$ et al. (2002).

${ }^{\mathrm{k}}$ Test ended postpeak before the load dropped by $20 \%$.

${ }^{\mathrm{l}}$ Test ended approximately at peak load.

occurred along a diagonal crack, limiting the ductility of the wall. The thick line in Fig. 7(a) is the predicted envelope of the response of wall VK3. As the 3PKT is based on kinematics of cracked walls, it is not suitable for predicting the initial elastic response prior to cracking. For this reason, the initial linear branch of the forcedisplacement curve is obtained from a Timoshenko beam model with uncracked sectional properties. The initial branch is utilized up to the intersection with the 3PKT curve. It can be seen that the 3PKT approach combined with the elastic beam model capture well the entire prepeak and postpeak response of specimen VK3. It should be noted that one such analysis requires a straightforward input (i.e., geometrical and material properties) and takes only about $5-10 \mathrm{~s}$ to complete on a typical computer.

Fig. 7(b) shows the predicted components of shear resistance of specimen VK3 and how they vary with increasing lateral displacement. These shear forces are the horizontal components of the spring forces in Fig. 4(a), where $V_{c i}$ corresponds to $F_{c i}, V_{\mathrm{CLZ}}$ to $F_{\mathrm{CLZ1}}$ and $F_{\mathrm{CLZ2}}, V_{s}$ to $F_{s}, V_{d}$ to $F_{d}$, and $V_{c f}$ to $F_{c n}$ and 
$F_{c t}$. It can be seen that the transverse reinforcement is predicted to yield at $\Delta$ of about $13 \mathrm{~mm}$ (component $V_{s}$ ) while flexural yielding occurs at $\Delta$ of about $20 \mathrm{~mm}$. Since the shear reinforcement is predicted to yield first, this wall is in the range of applicability of the 3PKT approach. The yielding of the flexural reinforcement is predicted to coincide approximately with the beginning of crushing in the critical loading zone (component $V_{\text {CLZ }}$ ). As the shear carried in the CLZ decreases, shear is redistributed to the aggregate interlock mechanism $V_{c i}$. This mechanism, however, is gradually weakened by the widening of the critical diagonal crack. Eventually, the aggregate interlock breaks down and triggers the shear failure of the wall. The small drop of resistance at $\Delta$ of about $37 \mathrm{~mm}$ is caused by the buckling of the compression reinforcement in the CLZ (spring $F_{s c}$ ). Throughout the loading history, the rigid block is predicted to remain in contact with the fan in the vicinity of the CLZ, where this interaction is represented by the negative shear component $V_{c f}$. It can also be seen that the dowel action $V_{d}$ is predicted to have a negligible contribution to the response of specimen VK3. The last point on the 3PKT curve corresponds to the displacement at which the wall is predicted to lose its axial load-bearing capacity.

As the three DOFs of the kinematic model are predicted throughout the loading history, it is of interest to compare the predicted and measured deformed shapes of the wall at different displacements $\Delta$ [Eqs. (1)-(4)]. Such a comparison at shear failure $(\Delta=42 \mathrm{~mm})$ is illustrated in Fig. 1(d). This figure also shows the measured and predicted strains $\varepsilon_{t}$ along the flexural reinforcement. It can be seen that both the deformed shape and the reinforcement strains are well captured by the 3PKT. Fig. 8 shows that similarly good agreement is achieved also at smaller displacements ( $\Delta=13.8 \mathrm{~mm}$ and $21.0 \mathrm{~mm}$ ). The deformed shape at $\Delta$ of $63 \mathrm{~mm}$ in the same figure corresponds to the instance at which the wall is predicted to lose its capacity to support the vertical load. This shape is not compared to measured deformations since such were not available; however, it can be seen that the vertical load is predicted to drive the rigid block down as it has been observed in the test (Bimschas 2010).

\section{Characterization of the Length of CLZ}

As mentioned earlier, Eq. (12) for the characteristic length of the critical loading zone was derived based on comparisons with wall tests. To collect as many tests as possible, existing databases and experimental studies were searched in the literature. For instance, the SERIES database containing 350 walls featuring different section types and failure modes was used (Perus et al. 2013; SERIES database 2013). The database was first filtered according to the applicability criteria of the 3PKT, namely: (1) rectangular sections; (2) single curvature bending; (3) $N / b h f_{c}^{\prime}<0.20$; (4) $a / h \leq 3.0$; (5) $a / b \leq 25$; (6) $f_{c}^{\prime} \leq 60 \mathrm{MPa}$; (7) no lap-splices in the base section; and (8) no diagonal shear reinforcement. The load-displacement response of each of the remaining 52 walls was computed with the 3PKT approach, and the characteristic length of the CLZ was varied until the best match was achieved between calculated and measured ultimate behavior. Since the kinematic model applies only to shear-dominated walls, tests for which the 3PKT predicted that the flexural reinforcement would yield before the shear reinforcement were excluded from the comparisons. The same procedure was also applied to two other databases ( $\mathrm{Lu}$ et al. 2010; NEES database, Gulec and Whittaker 2009) and to more recent tests from the literature (Luna et al. 2015). This resulted in a total of 34 walls to which the model is applicable. Table 1 summarizes the properties of the walls and lists the measured peak lateral load $V_{\max }$ and drift capacity $\delta_{0.8}$, where the latter is defined as the drift at $20 \%$ loss of lateral resistance.

The ideal values of the characteristic lengths obtained from the calibration of the model are shown in column $l_{b 1 e}^{\prime}$ of Table 1 . These lengths were plotted against different experimental variables, and a clear correlation was found between $l_{b 1 e}^{\prime}$ and the length of the diagonal of the walls. It can be seen from Fig. 9 that initially $l_{b 1 e}^{\prime}$ increase almost linearly with $\sqrt{ }\left(a^{2}+h^{2}\right)$, while for large walls with $\sqrt{ }\left(a^{2}+h^{2}\right)>3 \mathrm{~m}$ the trend becomes less than linear. Since the available data for large walls are limited, the observed trend is approximated with a straight line with a slope of 0.11 through the origin of the plot, and an upper bound of $370 \mathrm{~mm}$ as shown with the continuous line in the figure. The results from Eq. (12) for the walls from the database are listed in column $l_{b 1 e}$ of Table 1. Even though Eq. (12) approximates reasonably well the trend indicated by the individual walls, it is recognized that further research is necessary to better understand the factors governing the size of the CLZ.

\section{Comparisons with Tests}

The 3PKT approach with the proposed expression for the characteristic length of the CLZ was used to compute the complete loaddisplacement response of the walls from the database. The results for all 34 tests to which the model is applicable are shown in Fig. 10. On the horizontal axis of the plots is the lateral drift $\delta=\Delta / a(\%)$ and on the vertical axis is the lateral load $V(\mathrm{kN})$. The main properties of the walls are also summarized in the plots. Specimens VK1-7 were tested up to axial load failure; therefore, the 3PKT predictions correspond to the full prepeak and postpeak response curves. For the other specimens, the analysis was stopped once it reached a drop of lateral resistance comparable to that recorded in the tests. The exceptions are walls SW8-9, TW2-5, SW22, and WR0-WR20, which are predicted to fail due to crushing of the compression zone or rupture of the reinforcement in the base section. For these failure modes, the 3PKT does not predict the postpeak response.

It can be seen from Fig. 10 that the 3PKT approach captured reasonably well the response of most of the walls, except for walls 74, 82, 83, S9-10, TW5, SW5 ${ }^{\text {h }}$, SW26, and WR-0. Significant deviations in terms of stiffness, strength, and/or drift capacity are observed for walls $82,83, \mathrm{~S} 9, \mathrm{TW} 5, \mathrm{SW} 5^{\mathrm{h}}, \mathrm{SW} 26$, and WR-0. Walls 82 and 83 are predicted to exhibit a sudden loss of lateral resistance triggered by buckling of the compression reinforcement. While this effect is modeled in a simple and conservative manner in the 3PKT, a more complex model for

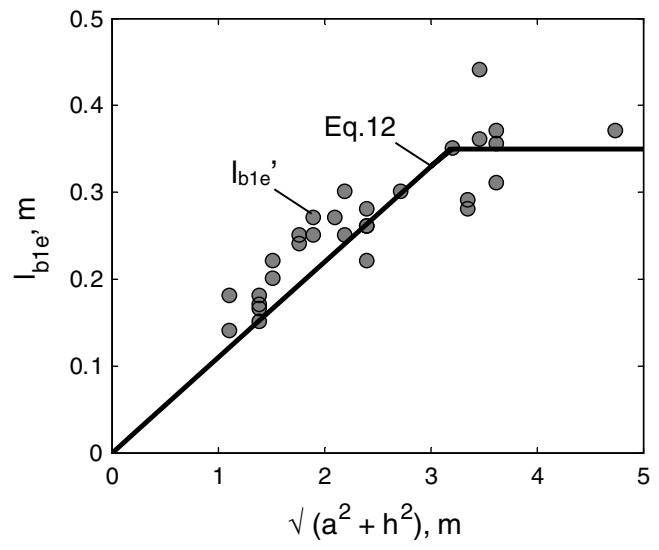

Fig. 9. Characteristic length of the critical loading zone 
bar buckling may be necessary to improve the predictions. Specimen S9 had no stirrups and failed along a diagonal crack consistent with the kinematic model. However, it is apparent from Fig. 10 that Eq. (12) underestimates the size of the CLZ of this wall as the shear strength of the wall is significantly underpredicted. Similarly underestimated is the strength of test specimen $\mathrm{SW} 5^{\mathrm{h}}$, which also exhibited a much lower stiffness than calculated with the 3PKT. The authors of this test used code equations to predict the initial
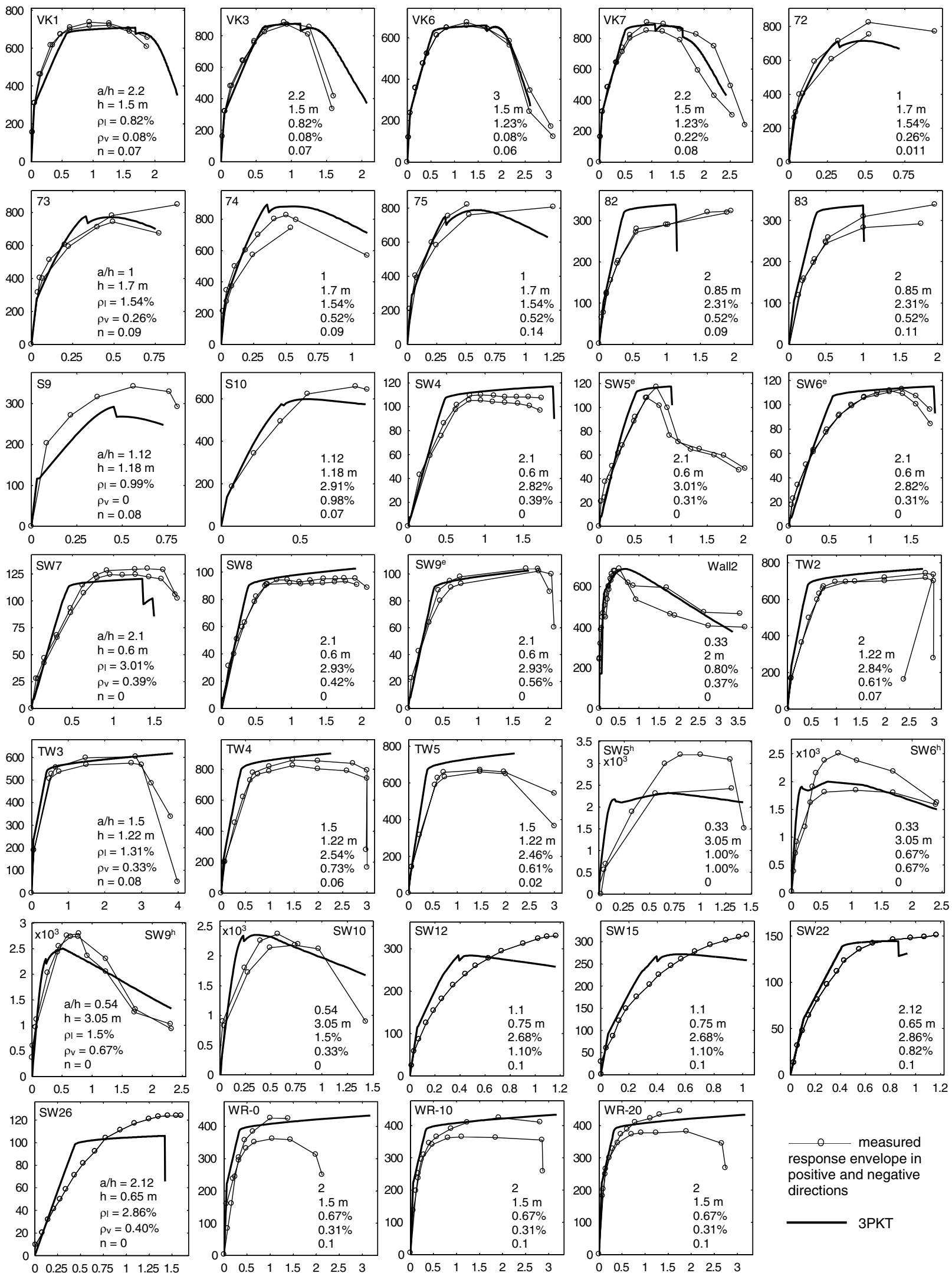

o measured response envelope in positive and negative directions

3PKT

Fig. 10. Shear force $(V, \mathrm{kN})$ versus lateral $\operatorname{drift}(\delta=\Delta / a, \%)$ response of walls; experimental results and 3PKT predictions 

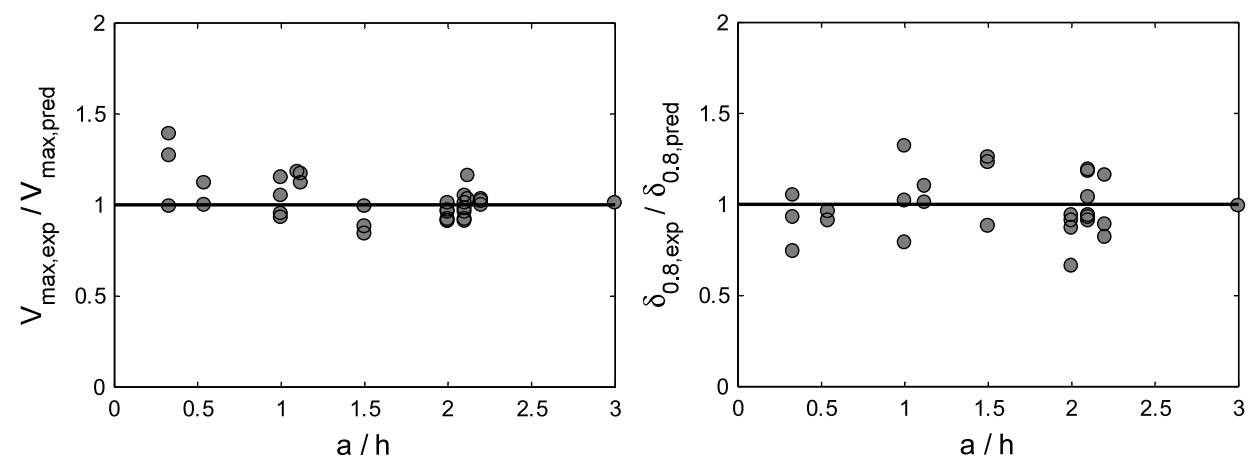

Fig. 11. Shear strength and drift capacity experimental-to-predicted ratios

stiffness, and they also concluded that the measured stiffness was substantially lower than the predictions. Walls TW5 and SW26 were mostly controlled by flexure, and the 3PKT predictions show that further research is necessary to extend the model to capture both shear-dominated and flexure-dominated behavior. Wall WR-0 had unconventional reinforcement consisting of two planes of orthogonal bars without ties connecting the two planes. Specimens WR-10 and WR-20 were identical to WR-0, but had conventional confining reinforcement in the end zones of the section. It can be seen from Fig. 10 that the 3PKT underestimated the drift capacity of WR-0 but adequately captured the response of specimens WR-10 and WR-20.

Accurate results were also obtained for the walls from the VK series and most walls from the $\mathrm{SW}^{\mathrm{e}}, \mathrm{TW}$, and $\mathrm{SW}^{\mathrm{h}}$ series. For some of the tests, the model predicted an almost bilinear behavior (i.e., wall SW6) while the experiments showed a more gradual loss of stiffness. This difference is explained with the fact that in the model the flexural reinforcement $A_{s}$ is lumped at its centroid; therefore, all bars are predicted to yield at the same time. In reality, the reinforcement is distributed and yields gradually from the tension edge of the section inwards. It is worth noting that the 3PKT approach adequately predicted the response of walls Wall2 and VK6, where the former wall was very short with and $a / h$ ratio of only 0.33 , and the latter wall was at the limit of applicability of the 3PKT with $a / h$ of 3.0 .

The experimental-to-predicted ratios for the peak load $V_{\max }$ and drift capacity $\delta_{0.8}$ of the walls from the database are listed in Table 1 . The average ratio for the peak load is 1.03 with a coefficient of variation $(\mathrm{COV})$ of $11.6 \%$, while the values for the drift capacity are 0.99 and $16.4 \%$. The $V_{\text {max,exp }} / V_{\text {max,pred }}$ and $\delta_{0.8 \text {, max }} / \delta_{0.8 \text {,pred }}$ ratios are plotted in Fig. 11 as a function of the $a / h$ ratio showing almost no bias of the 3PKT predictions with respect to this ratio. Similar observations were made when the experimental-topredicted ratios were plotted against the other experimental variables listed in Table 1. As these results are based on 34 tests, further validation studies will be necessary as more experimental data become available.

\section{Conclusions}

This paper presented a three-parameter kinematic theory (3PKT) for predicting the force-deformation behavior of shear-dominated $\mathrm{RC}$ walls, including the postpeak response and the loss of axial load-bearing capacity. The 3PKT is based on a kinematic model with three degrees of freedom (DOFs), which is an extension of a two-parameter model for deep beams (Mihaylov et al. 2013). This model describes the deformed shape of the member and links local and global deformations, which is important for addressing performance limits in the assessment of existing structures. The DOFs of the kinematic model are predicted by combining the kinematic conditions with equations for equilibrium and constitutive relationships for the mechanisms of load resistance, which are modeled as nonlinear springs. The 3PKT was applied to a test of a shear critical wall and captured well its complete load-displacement response, deformed shapes, and local deformations. Such an analysis requires a straightforward input and takes only about $5-10 \mathrm{~s}$ to complete on a typical computer. The 3PKT was also validated by using a database of 34 walls with rectangular cross-sections and aspect rations $a / h$ varying between 0.33 and 3 . It was shown that the proposed approach captured well the response of approximately $75 \%$ of the walls for which the model is applicable. The experimental-to-predicted ratios for the peak load had an average value of 1.03 with a COV of $11.6 \%$, while the ratios for the drift capacity had an average of 0.99 with a COV of $16.4 \%$. Further research is needed to extend the range of applicability of the 3PKT and to better understand the factors influencing the size of the critical loading zone in walls.

\section{Acknowledgments}

The research presented in this paper is part of a project funded by the Swiss Federal Roads Office (FEDRO) under project number AGB2008/001. This financial support is gratefully acknowledged. The authors would also like to thank the data providers and the SERIES Project [funded by the European Community's Seventh Framework Programme (FP7/2007-2013) under grant agreement $\mathrm{n}^{\circ}$ 227887] for giving access to the Data. The NEES network is also acknowledged for the data they have collected and made available to researchers.

\section{Notation}

The following symbols are used in this paper:

$A_{s}=$ one-half of total area of longitudinal reinforcement; $A_{v}=$ area of transverse reinforcement resisting shear;

$a=M / V$ - wall height subjected to shear;

$a_{g}=$ concrete maximum aggregate size;

$b=$ width of wall cross-section;

$c=$ depth of compression zone at base section;

$d=$ effective depth of section;

$d_{1}=$ distance from compressive edge of section to furthest tension longitudinal bar;

$d_{b}=$ diameter of main flexural reinforcement;

$F_{b}=$ compression force at base of fan; 
$F_{\text {CLZ }}=$ compression force in the concrete of CLZ;

$F_{c n}, F_{c t}=$ normal and tangential contact forces at the bottom of critical diagonal crack;

$F_{c i}=$ aggregate interlock force;

$F_{d}=$ dowel action force;

$F_{s}=$ force in the stirrups;

$F_{s c}=$ force in longitudinal reinforcement in CLZ;

$F_{t}=$ force in longitudinal tension reinforcement $A_{s}$;

$f_{b}=$ stresses in compression zone in base section;

$f_{t}=$ stresses along longitudinal tension reinforcement;

$f_{c}^{\prime}=$ concrete cylinder strength;

$f_{c, \mathrm{CLZ}}=$ average compressive stress in CLZ;

$f_{y}=$ yield strength of longitudinal reinforcement;

$f_{y v}=$ yield strength of transverse reinforcement;

$f_{u}=$ strength of longitudinal reinforcement;

$f_{u v}=$ strength of transverse reinforcement;

$f_{v}=$ stress in transverse reinforcement;

$h=$ depth of wall section;

$j d=$ lever arm between $F_{b}$ and $F_{t, \max }$;

$l_{b 1 e}=$ characteristic length of CLZ;

$l_{t}=$ cracked length along longitudinal reinforcement;

$l_{k}=$ length of transition zone between fan and rigid block;

$l_{0}=$ portion of $l_{k}$ below the critical diagonal crack;

$M=$ bending moment at the base of the wall;

$N=$ axial load;

$n_{b}=$ number of bars corresponding to $A_{s}$;

$n_{c r}=$ number of major diagonal cracks;

$s_{c r}=$ crack spacing in effective tension zone;

$V=$ shear force and lateral load;

$V_{\max }=$ peak shear force and peak lateral resistance;

$v_{c i}=$ aggregate interlock shear stress;

$w, \Delta_{c i}=$ crack width and crack slip;

$\alpha=$ angle of wall diagonal with respect to the vertical axis;

$\alpha_{1}=$ angle of critical crack;

$\alpha_{\Delta}=$ angle of displacement at CLZ;

$\alpha_{F}=$ angle of force $F_{\mathrm{CLZ}}$;

$\delta_{0.8}=$ lateral drift capacity;

$\delta_{x}, \delta_{z}=x$ - and $z$-displacements of points from wall;

$\Delta$ = applied lateral displacement;

$\Delta_{c}=$ horizontal displacement at CLZ;

$\Delta_{c x}=$ vertical displacement at CLZ;

$\Delta_{i}=$ deformations of springs;

$\Delta_{i 0}=$ displacements of ends of springs attached to the fan (offset displacements);

$\varepsilon_{b}=$ strains across base section;

$\varepsilon_{\mathrm{CLZ}}=$ average strain in CLZ;

$\varepsilon_{t}=$ strains along longitudinal tension reinforcement;

$\varepsilon_{t, \min (\max )}=$ minimum (maximum) strain along longitudinal tension reinforcement;

$\varepsilon_{t, \text { avg }}=$ average strain along longitudinal tension reinforcement;

$\varepsilon_{y}=$ yield strain of longitudinal reinforcement;

$\varepsilon_{u}=$ breaking strain of longitudinal reinforcement;

$\varepsilon_{u v}=$ breaking strain of transverse reinforcement;

$\varepsilon_{v}=$ strain in transverse reinforcement;

$\theta=$ rotation of rigid block;

$\theta_{b}=$ angle of force $F_{b}$ with respect to the vertical axis;

$\rho_{l}=2 A_{s} / b h$ ratio of total longitudinal reinforcement;

$\rho_{l, \mathrm{web}}=$ ratio of longitudinal web reinforcement;

$\rho_{l 1}=$ reinforcement ratio in effective tension zone; and

$\rho_{v}=$ ratio of transverse reinforcement.

\section{References}

AASHTO. (2007). AASHTO LRFD bridge design specifications, 4th Ed., Washington, DC, 1526.

ACI (American Concrete Institute). (2011). "Building code requirements for structural concrete (ACI 318-11) and commentary." Farmington Hills, MI, 503.

ASCE. (2007). "Seismic rehabilitation of existing buildings." ASCE/SEI 41-06, Reston, VA, 411.

Bentz, E. C., Vecchio, F. J., and Collins, M. P. (2006). "Simplified modified compression field theory for calculating shear strength of reinforced concrete elements." ACI Struct. J., 103(4), 614-624.

Bimschas, M. (2010). "Displacement-based seismic assessment of existing bridges in regions of moderate seismicity." IBK Rep. 326, Swiss Federal Institute of Technology ETH, Zurich, Switzerland.

Biskinis, D., and Fardis, M. N. (2010). "Flexure-controlled ultimate deformations of members with continuous or lap-spliced bars." Struct. Concr., 11(2), 93-108.

Blaauwendraad, J., and Hoogenboom, P. C. J. (1996). "Stringer panel model for structural concrete design." ACI Struct. J., 93(3), 1-11.

CEB-FIP. (1990). “CEB-FIP model code 1990.” Comité Euro-International du Béton, Lausanne, Switzerland, 437.

CEN (European Committee for Standardization). (2005). "Design of structures for earthquake resistance. 3: Assessment and retrofitting of buildings." Brussels, Belgium.

Gulec, C., and Whittaker, A. (2009). "Performance based assessment and design of squat concrete shear walls." Technical Rep. MCEER-09-0010, Univ. at Buffalo, Buffalo, NY.

Hannewald, P., Bimschas, M., and Dazio, A. (2013). "Quasi-static cyclic tests on RC bridge piers with detailing deficiencies." IBK Rep. 352, Swiss Federal Institute of Technology ETH, Zurich, Switzerland.

Hidalgo, P. A., Jordan, R. M., and Martinez, M. P. (2002). "An analytical model to predict the inelastic seismic behavior of shear-wall, reinforced concrete structures." Eng. Struct., 24(1), 85-98.

Hirosawa, M. (1975). "Past experimental results on reinforced concrete shear walls and analysis on them." Building Research Institute, Ministry of Construction, Tsukuba, Japan (in Japaness).

Lefas, I., Kotsovos, M., and Ambraseys, N. (1990). "Behavior of reinforced concrete structural walls: Strength, deformation characteristics, and failure mechanism." ACI Struct. J., 87(1), 23-31.

Li, B., Maekawa, K., and Okamura, H. (1989). "Contact density model for stress transfer across cracks in concrete." J. Faculty Eng., 40(1), 9-52.

Lu, X., Zhou, Y., Yang, J., Qian, J., Song, C., and Wang, Y. (2010). "Shear wall database." Network for Earthquake Engineering Simulation.

Luna, B. N., Rivera, J. P., and Whittaker, A. S. (2015). "Seismic behavior of low-aspect-ratio reinforced concrete shear walls." ACI Struct. J., 112(5), 593-603.

Maier, J., and Thürlimann, B. (1985). "Bruchversuche an Stahlbetonscheiben." Rep. No. 8003-1, Swiss Federal Institute of Technology ETH, Zurich, Switzerland.

Mander, J. B., Priestley, M. J. N., and Park, R. (1988). "Theoretical stressstrain model for confined concrete." J. Struct. Eng., 10.1061/(ASCE) 0733-9445(1988)114:8(1804), 1804-1826.

Martinelli, L. (2008). "Modeling shear-flexure interaction in reinforced concrete elements subjected to cyclic lateral loading." ACI Struct. J., 105(6), 675-684.

Mihaylov, B. I., Bentz, E. C., and Collins, M. P. (2010). "Behavior of large deep beam subjected to monotonic and reversed cyclic shear." $A C I$ Struct. J., 107(6), 726-734.

Mihaylov, B. I., Bentz, E. C., and Collins, M. P. (2013). "Two-parameter kinematic theory for shear behavior of deep beams." ACI Struct. J., $110(3), 447-456$.

Mihaylov, B. I., Hannewald, P., and Beyer, K. (2015). “Three-parameter kinematic theory for shear-dominated reinforced concrete walls: Implementation." Zenodo, Geneva, Switzerland.

Oh, Y.-H., Han, S. W., and Lee, L.-H. (2002). "Effect of boundary element details on the seismic deformation capacity of structural walls." Earthquake Eng. Struct. Dyn., 31(8), 1583-1602. 
Panagiotou, M., Restrepo, J. I., Schoettler, M., and Kim, G. (2012). "Nonlinear cyclic truss model for reinforced concrete walls." $A C I$ Struct. J., 109(2), 205-214.

Paulay, T. (1971). "Coupling beams of reinforced concrete shear walls." J. Struct. Div., 97(ST3), 843-862.

Perus, I., et al. (2013). "Enrichment of the distributed database with existing data." 〈http://www.series.upatras.gr/sites/default/files/Deliverable_D2 _7_v1_1.pdf> (Sep. 24, 2015).

Pilakoutas, K., and Elnashai, A. (1995). "Cyclic behaviour of reinforced concrete cantilever walls. I: Experimental results." ACI Struct. J., 92(3), 271-281.

Popovics, S. (1970). "A review of stress-strain relationships for concrete." ACI J., 67(3), 243-248.
Priestley, M. J. N., Calvi, G. M., and Kowalsky, M. J. (2007). Displacement-based seismic design of structures, IUSS Press, Pavia, Italy, 721. SERIES database. (2013). "RC column, beam and wall database." 〈http:// www.dap.series.upatras.gr/> (Sep. 24, 2015).

Tran, T. A., and Wallace, J. W. (2012). "Experimental study of nonlinear flexural and shear deformations of reinforced concrete structural walls." Proc., 15 World Conf. on Earthquake Engineering (WCEE), Lisbon, Portugal.

Vecchio, F. J., and Collins, M. P. (1986). "The modified compression-field theory for reinforced concrete elements subjected to shear." ACI Struct. J., 83(2), 219-231.

Wiradinata, S. (1985). "Behaviour of squat walls subjected to load reversals.” M.S thesis, Dept. of Civil Engineering, Univ. of Toronto, Toronto. 